\title{
„Ueber die künftige ständische Verfassung Sachsens. Eine Stimme zu dem bevorstehenden Landtage“ Ein wiederentdeckter außerparlamentarischer Entwurf einer Verfassung für das Königreich Sachsen aus dem Jahr 1830
}

\author{
von \\ HERMANN FREIHERR VON SALZA UND LICHTENAU
}

Die von manchen auch als „kleinstaatliche Revolution“ bezeichnete vormärzliche Reformbewegung in Sachsen, die die bis 1920 (freilich mit einigen Änderungen) in Kraft gebliebene Verfassung für das Königreich Sachsen vom 4. September $1831^{1}$ hervorbrachte, ist Gegenstand einer Fülle älterer und neuerer Literatur. ${ }^{2}$ Und auch weiterhin werden (und dürfen) die vormärzlichen Reformbestrebungen und die daraus hervorgegangene Staatsreform in Sachsen angesichts deren grundlegender Bedeutung für die Entwicklung Sachsens zum heutigen Rechtsstaat ${ }^{3}$ nichts an allgemeiner wie wissenschaftlicher Aufmerksamkeit einbüßen. Feierte der Sächsische Landtag $2006^{4}$ den 175. Jahrestag der Verfassung von 1831, unterblieb während der DDR-Zeit jegliches öffentliche und literarische Gedenken, zu dem etwa das Jubiläum 1981 Gelegenheit geboten hätte. Die Forschung zur Geschichte der

1 Gesetzsammlung für das Königreich Sachsen 1831, S. 241.

2 Überblick über Schrifttum zur Verfassung von 1831 bei WINFRIED MüLLER, Zwischen Stagnation und Modernität: Sachsens Weg zur Verfassung von 1831, in: Alois Schmid (Hg.), Die bayerische Konstitution von 1808. Entstehung - Zielsetzung - Europäisches Umfeld (Zeitschrift für bayerische Landesgeschichte, Beiheft 35), München 2008, S. 179-210, hier S. 179 f.; zur Verfassungsbewegung bei STEPHANIE VOGEL, Die liberale Bewegung in Sachsen 1830-1849 (unter besonderer Berücksichtigung des politischen Zentrums Leipzig), Diss. Bonn 1992; Rudolf MuHS, Zwischen Staatsreform und politischem Protest. Liberalismus in Sachsen zur Zeit des Hambacher Festes, in: Wolfgang Schieder (Hg.), Liberalismus in der Gesellschaft des deutschen Vormärz (Geschichte und Gesellschaft. Zeitschrift für historische Sozialwissenschaft, Sonderheft 9), Göttingen 1983, S. 194-238; ERNST Rudolf Huber, Deutsche Verfassungsgeschichte seit 1789, Bd. 2: Der Kampf um Einheit und Freiheit 1830 bis 1850 , Stuttgart ${ }^{3} 1988$, S. 76. Zur Frage, ob es sich hierbei um eine ,Revolution' handelte, mit einem Überblick über den Forschungsstand zustimmend Michael Hammer, Volksbewegung und Obrigkeiten. Revolution in Sachsen 1830/31 (Geschichte und Politik in Sachsen 3), Köln 1997, S. 84-96.

3 Näher Bernd-RÜdiger Kern/Adrian SCHMidT-Recla, Sachsen auf dem Weg zum Rechtsstaat 1438-1952, in: Festschrift. Ein Jahrzehnt Sächsische Gesetze 1990-2000, hrsg. vom SV Saxonia Verlag, Dresden 2000, S. 59-68, hier S. 60 f.; Christoph JestaedT, Die Sächsische Verfassung von 1831, in: Thomas Pfeiffer (Hg.), Sachsen als Verfassungsstaat, Leipzig 1998, S. 11-40, insbes. S. 30-34.

4 Anlässlich dieses Jubiläums erschien folgender Sammelband: 175 Jahre Sächsische Verfassung, hrsg. vom Landtag des Freistaates Sachsen, Dresden 2007. 
ersten sächsischen Verfassung kam trotz der Teilung Deutschlands 1945 bis 1989 allerdings nicht gänzlich zum Erliegen. In Westdeutschland führten etwa Hartwig Brandt, Ernst Rudolf Huber und Rudolf Muhs, ${ }^{5}$ in Ostdeutschland insbesondere Rudolf Forberger, Gerhard Schmidt, Roland Zeise und Hartmut Zwahr ${ }^{6}$ die bereits kurz nach Inkrafttreten der Verfassung von 1831 kraftvoll einsetzende ${ }^{7}$ und ab der zweiten Hälfte des 19. Jahrhunderts auch die Zeit der Reformbestrebungen im Vorfeld der Verfassung in den Blick nehmende ${ }^{8}$ historische Forschung - wenn auch freilich mit jeweils veränderter Perspektive - fort. Der bereits verstrichene 180. Jahrestag der Verkündung der Verfassung für das Königreich Sachsen von 1831 am 4. September 2011, anlässlich dessen keine weiteren Beiträge erschienen, soll nachträglich mit einer Erinnerung an die literarische Reformdebatte, die mit zu dieser Staatsreform beitrug, gewürdigt werden.

Hierbei wird der Blick vor allem auf den Beitrag eines Mannes gerichtet, der beziehungsweise dessen Werk - nach 1945 in Vergessenheit geraten - den Forschern aus der ersten Hälfte des 20. Jahrhunderts noch bekannt war. So setzte Paul Reinhardt 1916 folgende Ausführungen über die Schrift an die Spitze seines Kapitels „Die Umbildung des Staates“: „Die Ankündigung der Regierung, daß sie den Ständen einen Verfassungsentwurf unterbreiten werde, der den berechtigten Wünschen des Volkes Rechnung tragen sollte, ließ eifrige Federn nicht ruhen. Man machte ihr, noch bevor sie den Entwurf der Öffentlichkeit übergeben hatte, statt der bisher allgemeiner gehaltenen Bitten hinsichtlich der Bestimmungen der neuen Konstitution nun genauere, ins einzelne gehende Vorschläge, wünschte z. B., um gegen reaktionäre Bundesbeschlüsse gesichert zu sein, daß zu ihrer Ausführung

5 HARTwig BRANDT, Landständische Repräsentation im deutschen Vormärz. Politisches Denken im Einflußfeld des monarchischen Prinzips, Neuwied 1968; HUber, Verfassungsgeschichte (wie Anm. 2), S. 76-80; MuHs, Staatsreform (wie Anm. 2).

6 Z. B. RudOlF FORBERGER, Industrielle und bürgerliche Revolution, in: Sächsische Heimatblätter 29 (1983), S. 21 f.; GERHARD SCHMIDT, Die Staatsreform in Sachsen in der ersten Hälfte des 19. Jahrhunderts. Eine Parallele zu den Steinschen Reformen in Preußen (Schriftenreihe des Staatsarchivs Dresden 7), Weimar 1966; DerS., Reformbestrebungen in Sachsen (Quellen und Forschungen zur sächsischen Geschichte 7), Dresden 1969; z. B. Roland ZeISE, Der historische Platz der revolutionären Volksbewegungen 1830/1831 und der Staatsreform in Sachsen, in: Sächsische Heimatblätter 29 (1983), S. 1-9; z. B. HARTMUT ZwAHR, Bourgeoisie und Proletariat am Beginn der bürgerlichen Umwälzung in Sachsen. Die Septemberereignisse von 1830 und die Anfänge der deutschen Arbeiterbewegung, in: Zeitschrift für Geschichtswissenschaft 25 (1977), S. 656-675.

7 Überblick bei Michael Stolleis, Geschichte des öffentlichen Rechts in Deutschland, Bd. 2: Staatsrechtslehre und Verwaltungswissenschaft 1800-1914, München 1992, S. 211214.

8 CÄsar Dietrich von WitZleben, Die Entstehung der constitutionellen Verfassung des Königreichs Sachsen. Zur Feier des fünfzigjährigen Bestehens der Verfassungsurkunde vom 4. September 1831, Leipzig 1881; PAUL ReINHARDT, Die sächsischen Unruhen der Jahre 1830-1831 und Sachsens Ubergang zum Verfassungsstaat, Halle 1916; AlEXANDER SCHLECHTE, Die Vorgeschichte der sächsischen Verfassung vom 4. September 1831, Borna/ Leipzig 1927; Hellmut KRETZSCHMAR, Die sächsische Verfassung vom 4. September 1831, in: Neues Archiv für sächsische Geschichte 52 (1931), S. 207-248; VOLKMAR EICHSTÄDT, Die deutsche Publizistik von 1830, Berlin 1933, S. 53-64. 
ständische Mitwirkung erforderlich sei. Gleiche Rechte, gleiche Pflichten, das möge das Losungswort sein, mit dem man an die Ausarbeitung des Entwurfes gehen sollte."9 Alexander Schlechte führt die Publikation 1927 zumindest in seinem Quellenverzeichnis auf. Volkmar Eichstädt ordnete 1933 das Werk im Vergleich zu „radikalen Programmen“ einem „gemäßigteren Standpunkt“ zu und konnte den Verfasser erstmals identifizieren: ${ }^{10}$ Es handelte sich um den Beitrag des jungen Referendars bei der königlichen Landesregierung Carl von Salza und Lichtenau, der 1830 unter C. v. S. mit der Schrift „Ueber die künftige ständische Verfassung Sachsens. Eine Stimme zu dem bevorstehenden Landtage"11 einen erst kürzlich vom Verfasser wiederentdeckten Entwurf einer Verfassung für das Königreich Sachsen vorlegte.

\section{$I$.}

Carl von Salza und Lichtenau12 wurde am 19. Juni 1802 in Wurzen als Sohn des königlich sächsischen Hauptmanns Hermann von Salza und Lichtenau und der Johanna Christiane, geborene Müller, geboren. Er entstammte dem seit 1298 in der Oberlausitz nachgewiesenen, zum oberlausitzischen landsässigen Adel zählenden Geschlecht Salza, nämlich der Nebenlinie Lichtenau-Wingendorf, die jedoch nach dem 1777 erfolgten Verkauf des Rittergutes Wingendorf am Queis in der Oberlausitz um 1800 über keinen Grundbesitz mehr verfügte. ${ }^{13}$ Nach abgeschlossenem Jurastudium in Leipzig wurde Salza zunächst Auditor beim Oberhofgericht in Leipzig, um 1826 gemeinsam mit dem gleichaltrigen Albert von Carlowitz und dem ein Jahr älteren Otto Friedrich Heinrich von Watzdorf, auf die später noch einzugehen sein wird und die er beide bereits aus dem Studium kannte, zum Assessor bei der königlichen Landesregierung in Dresden ernannt zu werden. Salza und Carlowitz wurden 1828 zu Referendaren bei der Landesregierung befördert. Alle drei Juristen erhoben ab 1829 ihre Stimme im Rahmen der vormärzlichen Reformbestrebungen in Sachsen.

Nach 1831 wählte Salza anders als Carlowitz und Watzdorf nicht die parlamentarische, politische Laufbahn, die er wohl vor allem mangels eines Rittergutes nicht einschlug, sondern die in der Judikative. 1835 wurde er als Appellationsrat

9 ReINHARDT, Unruhen (wie Anm. 8), S. 242.

10 EichstäDT, Publizistik (wie Anm. 8), S. 57.

11 Carl von Salza und Lichtenau, Ueber die künftige ständische Verfassung Sachsens. Eine Stimme zu dem bevorstehenden Landtage, Dresden 1830.

12 Das Folgende nach Hermann Freiherr von Salza und Lichtenau, Carl von Salza und Lichtenau, in: Sächsische Biografie, hrsg. vom Institut für Sächsische Geschichte und Volkskunde, www.isgv.de/saebi (Zugriff 11. Juni 2012).

13 Zur Familie: Hermann Freiherr von Salza und Lichtenau, Salza (Saltza) von, in: Sächsische Biografie (wie Anm. 12); zum Rittergut Wingendorf: WALTER VON BOETTICHER, Geschichte des Oberlausitzischen Adels und seiner Güter, Bd. 2, Oberlößnitz 1913, S. 687-711; ebd., Bd. 3, Oberlößnitz 1919, S. 676 f. 
Richter am Appellationsgericht zu Leipzig, um 1843 zum Oberappellationsrat und damit zum Richter am königlich sächsischen Oberappellationsgericht in Dresden berufen zu werden. 1864 übernahm Salza schließlich den Vorsitz des Kriminalsenats des Gerichts. Doch schon am 10. Juni 1865 verstarb er in Dresden. Verheiratet war Carl mit Ida Mathilde Charlotte, geb. John (1803-1871). Von seinen Kindern erreichte eine Tochter das Erwachsenenalter. Neben zahlreichen maßgebenden Gerichtsentscheidungen, an denen Carl von Salza mitwirkte, sowie juristischen Aufsätzen - so für Julius Weiskes „Rechtslexikon für Juristen aller teutschen Staaten“ 14 - veröffentlichte er bereits 1825 das zweibändige „Handbuch des Polizeirechts“15. Diese Schrift befasste sich erstmals und grundlegend mit einem Hauptthema des sächsischen Verwaltungsrechts. Das 1838 erschienene Buch „Die Lehre von Familien-, Stamm- und Geschlechts-Fideicommissen“16 stellt eine der maßgeblichen Veröffentlichungen zum Fideikommissrecht des 19. Jahrhunderts dar. Durch seine juristische Publikationstätigkeit blieb Carl von Salzas Werk zumindest in der Rechtswissenschaft des 19. und frühen 20. Jahrhunderts über die Grenzen Sachsens hinaus präsent.

\section{II.}

Mannigfaltige Reformbestrebungen führten quer durch alle Stände zu einer umfangreichen, selbst bezogen auf Sachsen nur schwer nach inhaltlichen Gesichtspunkten strukturierbaren Publizistik im Vorfeld der Vormärz-Verfassungen. ${ }^{17}$ Das Bild vom Staat hatte sich seit der Zeit der Aufklärung gewandelt. Die Kantianer gingen vom Prinzip einer voluntaristischen, konsensualen und rationalistischen Begründung der Staatsgewalt auf Grundlage eines fiktiven Vertrags freier Menschen, also von einem Staat, der gleichsam als eine künstliche, von Menschenhand zusammengesetzte Maschine funktioniere, aus. Dahingegen vollzog sich insbesondere auf Grundlage individualisierender und historisierender Betrachtung vor allem bei einem großen Teil der Liberalen ein Wandel hin zu einer Vorstellung des Gemeinwesens als geschichtlich gewachsener Organismus, der anders als eine Maschine flexibel auf veränderte Umweltbedingungen reagiere. Ausdruck waren aufkeimender nationaler Pathos und Rückbesinnung auf das Mittelalter. Aus dem Nachlass des Frühromantikers Novalis, der deshalb im vorliegenden Zusammenhang als naheliegendes Beispiel für einen Vertreter dieser Richtung angeführt

14 Carl von Salza und Lichtenau, Familienfideicommisse, in: Julius Weiske (Hg.), Rechtslexikon für Juristen aller teutschen Staaten enthaltend die gesammte Rechtswissenschaft, Bd. 4, Leipzig 1843, S. 237-255; DERS., Gewohnheitsrecht, in: ebd., S. 836-856.

15 CARl von SAlza und Lichtenau, Handbuch des Polizeirechts: mit besonderer Berücksichtigung der im Königreiche Sachsen geltenden Polizeigesetze, Leipzig 1825.

16 Carl von Salza und Lichtenau, Die Lehre von Familien-, Stamm- und Geschlechtsfideicommissen nach den Grundsätzen des gemeinen deutschen Privatrechts und mit Rücksicht auf die Abweichungen der einzelnen Particularrechte, Leipzig 1838.

17 Das Folgende nach STOLLEIS, Geschichte (wie Anm. 7), S. 121-186. 
werden kann, gab Carl von Salza später ein Gedicht heraus. Angesichts der vor allem durch die Französische Revolution ausgelösten grundlegenden Veränderung der bisher als unerschütterlich geltenden Ordnung nahm Novalis an, das Mittelalter sei die Zeit der Einheit aller Widersprüche, eine glückliche Urzeit, welcher eine Zwischenphase des Zerfalls folge, die nunmehr von einem neuen Zeitalter, einer Wiederherstellung der Urzeit, aber auf höherem Niveau, abgelöst werde. Er erstrebte in seinem Bedürfnis nach Harmonie die Zusammenführung scheinbar getrennter Teile der Welt. ${ }^{18}$

Dem entsprach das Streben nach „Ausgleich des Dualismus von monarchischem Prinzip und Volksfreiheit“, ${ }^{19}$ ein Ansatz vor allem der Nationalromantiker um Ernst Moritz Arndt und der von der Romantik inspirierten germanistischen Historischen Rechtsschule. ${ }^{20}$ Das rechtshistorische Thema dieses Beitrags, also der Umstand, dass es hier im Wesentlichen um Beiträge zur Verfassungsdiskussion von Juristen geht, erfordert einige Sätze zur Historischen Rechtsschule, die von der zweiten Hälfte des 18. Jahrhunderts bis zur zweiten Hälfte des 19. Jahrhunderts, als sie von der Begriffsjurisprudenz abgelöst zu werden begann, die prägende juristische Methode darstellte. ${ }^{21}$ In Abkehr vom Vernunftrecht (und mithin gegen die Ergebnisse der Französischen Revolution) fassten ihre Vertreter das Recht nicht auf als einen „zufällig und willkürlich“ vom Gesetzgeber geschaffenen Bestand an Vorschriften, sondern als „dem Volk eigentümliche“ „gemeinsame Überzeugung“ „so wie seine Sprache, Sitte, Verfassung“ (Friedrich Carl von Savigny), ${ }^{22}$ die nicht ewig gleichbleibe, sondern sich laufend organisch gemäß der sich verändernden Bedürfnisse des Volkes weiterentwickele. Die Historische Schule nahm dabei in Anlehnung vor allem an Montesquieu und Voltaire, also an vorrevolutionäre Programme an, dem Volk wohne eine gemeinsame Seele inne, und dieser entspreche ein gemeinsames Recht (Volksgeistlehre). Richtige Methode, das auf diese Weise organisch entstandene Recht zu erkennen (und anzuwenden), war eine genetische historische, die Savigny treffend umschrieb als eine von der Frage ausgehende, in „welchem Verhältniß [...] die Vergangenheit zur Gegenwart, oder das Werden zum Seyn" 23 stehe. Die Historische Schule spaltete sich frühzeitig in zwei Gruppen, die Germanisten und die Romanisten, eine Differenzierung, die anhand der jeweils zugrunde gelegten Rechtsquellen vorgenommen wurde: Die Germanisten meinten, die verschiedenen Rechtsquellen

18 Hugo ERnSt KäUfer, Novalis - Vorbote Europas, in: Ders., Lesezeichen, Düsseldorf 2002; Primärquelle: CARL PASCHEK (Hg.), Novalis (Friedrich von Hardenberg), Fragmente und Studien. Die Christenheit oder Europa, Stuttgart 1984, Absätze 1-11.

19 STOLLeIS, Geschichte (wie Anm. 7), S. 177.

20 Ebd.

21 Das Folgende nach BERnd-RÜDIger KeRn, Die historische Rechtsschule und die Germanisten, in: Gerhard Dilcher/Bernd-Rüdiger Kern, Die Juristische Germanistik des 19. Jahrhunderts und die Fachtradition der Deutschen Rechtsgeschichte, in: Zeitschrift der Savigny-Stiftung für Rechtsgeschichte. Germanistische Abteilung 101 (1984), S. 4-29.

22 Zitiert nach KeRN, Germanistik (wie Anm. 21), S. 6.

23 Zitiert nach Kern, Germanistik (wie Anm. 21), S. 7, Anm. 15. 
des mittelalterlichen heimischen Rechts entsprächen dem Volksgeist, während die Romanisten das im deutschen Reich rezipierte fremde, das heißt römische Recht als Ausdruck dessen ansahen. Es zeigen sich denn auch deutliche Unterschiede in Problemverständnis, Methode und Mentalität: das Interesse der Romanisten an einer durch Kontinuität gekennzeichneten Tradition von Jurisprudenz und dogmatischen Figuren, während die Germanisten angesichts einer „gebrochen-vielfältigen Quellengrundlage“ 24 stärker in Verfassungs- und Sozialgeschichte ausgriffen und die Zusammenarbeit mit der Geschichtswissenschaft suchten.

\section{III.}

Die Vertreter der Historischen Rechtsschule waren im Vormärz bis hin zur Paulskirche in starkem Maß politisch engagiert. Allgemeine liberale Forderungen, denen sich auch die Vertreter der germanistischen Historischen Rechtsschule anschlossen, waren hinsichtlich der Individualrechte solche nach Freiheit und Gleichheit, was sich etwa in der Gewissens- und Pressefreiheit sowie in einem Zugang zu allen Staatsämtern frei von Standesschranken zeigen sollte. Erstrebt wurde eine rein staatliche, unabhängige Justiz. Es sollte auch möglich sein, Minister und Volksvertreter für ihr Amtshandeln zur Verantwortung zu ziehen. Das Verhältnis zwischen Monarchie und Volkvertretung sollte auch nach dem Willen der „historisch-organischen“ Nationalliberalen durch eine Verfassung festgeschrieben werden. Dem unbedingten Gleichheitspostulat der Vernunftrechtler stellten die Vertreter der germanistischen Historischen Schule die mittelalterlichen heimischen Quellen entgegen, die die mittelalterlich-ständischen Landtage, also ständische Unterschiede kannten. Betont liberale Germanisten rekurrierten auf das Idealbild der ursprünglichen germanischen Volksfreiheit mit ihrer ausgeprägten genossenschaftlichen Verfassung, die in einer allerdings organisch gegliederten, nicht radikal-egalitären Form wiederherzustellen sei. Ihnen allen ging es indes anders als den Vernunftrechtlern weniger um die Umsetzung formaler Gleichheit als vielmehr um sozialpolitischen Ausgleich. ${ }^{25}$ In der Konzeption der konkreten Gestaltung der sozialständischen Gliederung der Volksvertretung, die weder altständisch noch demokratisch sein sollte, gingen die einzelnen Vertreter unterschiedliche Wege. Sollte es ein Ein- oder ein Zweikammersystem geben, in dem die überkommenen, bisher maßgeblichen Stände die erste Kammer mit größerem Mitspracherecht bildeten? Wie sollte das kraftvoll entstehende bürgerlich-kapitalistische Lager beteiligt werden, etwa mit der Forderung nach einem Nachweis bestimmter Einkünfte in Geld als Zugangsvoraussetzung? Wie sollte der Einfluss

${ }^{24}$ Gerhard Dilcher, Einleitung, in: Dilcher/Kern, Germanistik (wie Anm. 21), S. 1-4, hier S. 2.

25 Gerhard Dilcher, Römisches Recht oder deutsches Recht? Zum Verhältnis von Quellengrundlage und methodisch-rechtspolitischer Werthaltung in der Schule der Germanisten, in: Dilcher/Kern, Germanistik (wie Anm. 21), S. 29-46, hier S. 41. 
der bisherigen Stände, der geistlichen Stifter, des standesherrlichen und ritterschaftlichen Adels, die alle noch immer über einen wesentlichen Teil des Grundbesitzes verfügten, gewichtet werden? Und sollte etwa auch unangesessener (alter) Adel, ein neues Phänomen des 19. Jahrhunderts, beteiligt werden? Eine historische Betrachtungsweise führte oft $\mathrm{zu}$ einer weiterhin ländlich-agrarisch dominierten, dann doch eher an altständischen Traditionen orientierten Gestaltung der Volksvertretung, in die jedoch auch gemäß der veränderten sozialen Umstände Vertreter insbesondere des handel- und gewerbetreibenden Bürgertums aufgenommen werden sollten. ${ }^{26}$

Auch im Paulskirchenparlament und in den Landtagen der deutschen Territorialstaaten zeigte sich die Gliederung der Liberalen in Vernunftrechtler, Germanisten und Romanisten. Bernd-Rüdiger Kern wies nach, dass bei Vorhandensein eines „vielarmigen Stroms Liberalismus“27 im Paulskirchenparlament, der einen demokratischen und einen monarchisch-konstitutionellen, altliberalen Arm aufwies, die demokratischen Linksliberalen vernunftrechtlich geprägt waren, während die um Ausgleich mit der Monarchie bemühten konstitutionellen Rechtsliberalen der germanistischen Historischen Rechtsschule angehörten. Die Romanisten waren konservativ. Diese Zuordnung hatte sich bereits innerhalb der vormärzlichen Landstände der deutschen Territorialstaaten entwickelt. In der badischen zweiten Kammer war es der Germanist Carl Joseph Anton Mittermaier, der 1831 auf liberale, vernunftrechtliche Forderungen nach grundlegender Umgestaltung des badischen Universitätswesens nach dem „Prinzip der Freiheit“ einwandte, eine solche dürfe nicht „völlig“, sondern nur unter Beachtung der erhaltenswerten, „von der Weisheit der Jahrhunderte“ hervorgebrachten Strukturen vorgenommen werden. ${ }^{28}$ In der zweiten Kammer des preußischen Landtags argumentierte der Germanist Georg Beseler gegen die reaktionären Konservativen. So lehnte er noch in der Sitzungsperiode 1850/51 mit historisch-rechtlicher Begründung die Einrichtung von Herrenhaus und Drei-Klassen-Wahlrecht ab.29 Bezogen auf die sächsischen Landstände des Vormärz, insbesondere die Mitglieder des letzten vorkonstitutionellen Landtags 1830/31 wären entsprechende Untersuchungen noch zu veranstalten. ${ }^{30}$ Hinsichtlich der außerparlamentarischen Strömungen im Vorfeld der Sächsischen Verfassung von 1831 erfolgt an dieser Stelle der Versuch eines Überblicks, der jedoch insbesondere dazu dient, eine Grundlage für die theoriegeschichtliche Einordnung des Verfassungsentwurfs Salzas zu bieten.

26 Vgl. STOLleis, Geschichte (wie Anm. 7), S. $181 \mathrm{f}$.

27 Kern, Germanistik (wie Anm. 21), S. 25.

28 Zitiert nach KeRn, Germanistik (wie Anm. 21), S. 27.

29 Kern, Germanistik (wie Anm. 21), S. 24-29.

30 Sie würden sich hervorragend anschließen an die Arbeiten Josef Matzeraths zur sächsischen Landtagsgeschichte; vgl. JOSEF MATZERATH, Aspekte sächsischer Landtagsgeschichte. Die Mitglieder der kursächsischen Landstände 1763-1831, Dresden 2009; DERS., Aspekte sächsischer Landtagsgeschichte. Die Spätzeit der sächsischen Ständeversammlung (1763-1831), Dresden 2006; DERS., Aspekte sächsischer Landtagsgeschichte. Umbrüche und Kontinuitäten 1815 bis 1868, Dresden 2000. 
Die Staatswissenschaft an der Universität Leipzig war zwar in der Zeit vor 1831 noch stark von der vernunftrechtlichen Linie der Frühliberalen geprägt. Sie wurde insbesondere von dem Historiker und Staatswissenschaftler Karl Heinrich Ludwig Pölitz und dem Philosophen Wilhelm Traugott Krug31 beeinflusst. ${ }^{32}$ Beider Vorstellung wohnten jedoch weniger feste Grundsätze inne denn gleichsam realpolitisch ein je nach Lage der Dinge ausfallendes Bemühen um Ausgleich und Vermittlung zwischen widerstreitenden Ansprüchen. Nach Muhs bedeutete dies „faktisch [...] ein ängstliches Schwanken zwischen der grundsätzlichen Befürwortung einer sozialständisch orientierten Verfassungsreform, die der gesellschaftlichen Entwicklung Rechnung tragen sollte, und der vorsorglichen Ablehnung jedes entschiedenen Drängens darauf, das, ganz im Sinne der Obrigkeit, dem Verdikt des Umsturzes verfiel.“ Diese Geisteshaltung „schnitt letzten Endes den Liberalismus auf das Maß des Status quo zurecht." 33 Bemerkenswert ist dabei, dass Krug, durchdrungen vom Nationalstaatsgedanken, den Anstoß zur philhellenischen Bewegung in Deutschland und vor allem auch in Sachsen gab. Daran schloss sich rund ein Jahrzehnt danach gerade in Sachsen eine große Anteilnahme an der polnischen Erhebung von 1830 an, der auch Carl von Salza eine Veröffentlichung ${ }^{34}$ widmete. ${ }^{35}$ Währenddessen war es an der Leipziger Juristenfakultät still. Mit Ausnahme des Staatsrechtlers Karl Eduard von Otto, der sich für eine umfassende Universitätsreform im liberalen Geist einsetzte, sind keine veröffentlichten Äußerungen eines Leipziger Jura-Dozenten im Vorfeld der Verfassung von 1831 bekannt. ${ }^{36}$ Erst nach der Staatsreform von 1831 zog es - berühmte - Vertreter der Historischen Rechtsschule nach Leipzig, die als Liberale auch an der weiteren öffentlichen Diskussion im deutschen Vormärz teilnahmen. ${ }^{37}$ Die Juristen in Sachsen, die sich vor 1831 äußerten, waren denn Praktiker wie beispielsweise der Leipziger Gerichtsdirektor August Ludwig Mothes oder der revolutionäre Dresdner Rechtsanwalt Bernhard Moßdorf. ${ }^{38}$

31 Über ihn Uwe Backes, Der Philosoph Wilhelm Traugott Krug: Seine Stellung im vormärzlichen Liberalismus und sein Wirken für die Judenemanzipation in Sachsen, in: Stephan Wendehorst (Hg.), Bausteine einer jüdischen Geschichte der Universität Leipzig (Leipziger Beiträge zur Jüdischen Geschichte und Kultur 4), Leipzig 2006, S. 483-504.

32 Über beider Rolle im Vormärz BRANDT, Landständische Repräsentation (wie Anm. 5), S. 214-226.

33 MuHS, Staatsreform (wie Anm. 2), S. 206.

34 Carl von Salza und Lichtenau, Polen und die öffentliche Meinung, Altenburg 1832.

35 Hierzu Anneliese Gerecke, Das deutsche Echo auf die polnische Erhebung von 1830, Wiesbaden 1964, die auf S. 40 auch Salzas Arbeit kritisch würdigt.

36 Vgl. etwa den gründlichen Überblick bei EICHSTÄDT, Publizistik (wie Anm. 8), S. 53 64, 180-184.

37 Hierzu Bernd-RÜdiger Kern, Juristenfakultät, in: Ulrich von Hehl/Uwe John/ Manfred Rudersdorf (Hg.), Geschichte der Universität Leipzig 1409-2009, Bd. 4: Fakultäten, Institute, Zentrale Einrichtungen, 1. Halbbd., Leipzig 2009, S. 103-147, hier S. 118126.

38 EICHSTÄDT, Publizistik (wie Anm. 8), S. 57, 180-184. 


\section{$I V$.}

Die früheste Manifestation von „konstitutionellem Liberalismus“ in Sachsen, die der Erkenntnis geschuldet war, dass der sächsische Landtag in seiner bisherigen Besetzung nicht mehr sämtliche maßgeblichen Schichten des Volkes repräsentierte, war ein Antrag einiger sächsischer Städte aus dem Jahr 1818. Hiernach sollten künftig auch „Vertreter des Bauern-, des Handels- und Fabrikstandes“ berechtigt sein, ihre Vertreter in die Ständeversammlung zu entsenden. ${ }^{39}$ Zuerst meldete sich in Sachsen also das hier bereits sehr frühzeitig, seit Jahrzehnten insbesondere durch den industriellen Fortschritt erstarkende, nunmehr auch zur Mitbestimmung strebende handel- und gewerbetreibende gebildete Bürgertum, das vor allem in der Handels- und Buchstadt Leipzig ansässig war. Dahingegen wiesen die Bauern von allen sächsischen Bevölkerungsteilen am längsten und stärksten eine loyale, politisch eher desinteressierte, christlich-konservative Grundhaltung auf. ${ }^{40}$ Ihre Interessen wurden mangels eigener Repräsentation im Landtag von den Vertretern der Städte mit wahrgenommen. Dieser Antrag wies keine theoretisch wohl begründete liberale Haltung auf, sondern war schlicht Ausdruck des politischen Mitbestimmungswillens des emanzipierten Bürgertums, das erst in dem im genannten Sinne veränderten Landtag „eine vollständigere und zweckmäßigere Repräsentation des Landes“41 erblickte. Je stärker jedoch auch die überkommene Kommunalverfassung, die noch auf dem aus dem Mittelalter stammenden Prinzip der Selbstergänzung aus den ratsfähigen Geschlechtern einer Stadt beruhte, wegen der mangelnden Beteiligung nicht ratsfähiger Bürger mithin auch im Landtag zum Gegenstand liberaler Kritik wurde, desto zurückhaltender traten die Städte auf. ${ }^{42}$

War demnach Liberalismus auch in Sachsen bislang ein wesentlicher Bestandteil der Identität der bürgerlichen Bewegung gewesen, kamen nach langem Stillstand nach 1820 die maßgeblichen Anstöße für die entscheidende, ab Ende der 1820erJahre geführte Reformdebatte, die zur Staatsreform von 1831 führte, jedoch von einigen Angehörigen des Adels, die als Beamte im höheren Staatsdienst tätig waren, und zwar durch außerparlamentarische Vorschläge, die teils anonym veröffentlicht wurden. Dies waren insbesondere die bereits genannten Herren von Carlowitz und von Watzdorf, die nicht nur Beamte bei der Landesregierung, sondern als Rittergutsbesitzer zugleich Mitglieder des ab 1830 tagenden letzten vorkonstitutionellen Landtags waren, der auch über die Verfassung von 1831 beriet. $^{43}$ Muhs qualifiziert die Tatsache, dass in Sachsen auf diese Weise „eine aristokra-

39 Zitiert nach THEODOR FLATHE, Geschichte des Kurstaates und Königreiches Sachsen, Bd. 3: Neuere Geschichte Sachsens von 1806-1866, Gotha 1873, S. 377.

40 Hierzu näher Vogel, Bewegung (wie Anm. 2), S. 33-39.

41 Zitiert nach Flathe, Geschichte (wie Anm. 39), S. 377.

42 MuHs, Liberalismus (wie Anm. 2), S. 204.

$43 \mathrm{Zu}$ den späten vorkonstitutionellen sächsischen Ständeversammlungen und deren Mitgliedern MatZerath, Mitglieder (wie Anm. 30); Ders., Spätzeit (wie Anm. 30). 
tische Körperschaft zum Medium des konstitutionellen Liberalismus" geworden sei, als „eine bemerkenswerte Ausnahmeerscheinung in der deutschen Verfassungsgeschichte des Vormärz“. ${ }^{44}$ Innerhalb der Gruppe der (zunächst) außerparlamentarischen adligen Reformer muss jedoch weiter unterschieden werden, und zwar nach Besitzern landtagsfähiger Rittergüter ohne Stellung im höheren Staatsdienst, nach solchen, die zugleich höhere Beamte waren, und schließlich jenen, die - ohne Grundbesitz - ausschließlich im höheren Staatsdienst tätig waren. ${ }^{45}$ Die These Stephanie Vogels, die „landtagsfähige und im Staatsdienst tätige Jungritterschaft“ habe sich "als Träger des konstitutionellen Liberalismus herauskristallisiert", 46 muss dahin modifiziert werden, dass es, wie etwa an Salza zu zeigen ist, junge (juristisch aus-)gebildete Aristokraten im höheren Staatsdienst unabhängig von ihrer Landtagsfähigkeit waren, die sich rege an der außerparlamentarischen Reformdebatte im Vorfeld des letzten vorkonstitutionellen Landtags 1831 beteiligten. Auch in diesem Sinne ist Vogels weitere These aufzufassen, „die Träger des aristokratischen Liberalismus stellten eine heterogene Gruppe dar, die keine aufeinander abgestimmte Politik vertrat, sondern nur in dem allgemeinen Rahmen der konstitutionellen Staatsauffassung zusammenzufassen war" ${ }^{47}$ Sie kann sich mithin allein auf die Inhalte der einzelnen Vorschläge beziehen, auf die nun - unter besonderer Berücksichtigung von Carl von Salzas Entwurf - einzugehen ist.

\section{V.}

Bereits 1829 hatte der Oberkammerherr Emil von Uechtritz eindringlich in seiner Denkschrift „Darstellung der jetzigen Lage von Sachsen“48 auf die Missstände in der Regierung Einsiedel hingewiesen, ohne jedoch weiterführende Vorschläge zu deren Behebung zu unterbreiten. Der Kreishauptmann zu Plauen Eduard von Wietersheim, der auch Mitglied des letzten vorkonstitutionellen Landtags war, ${ }^{49}$

44 Muhs, Liberalismus (wie Anm. 2), S. 209. Vgl. Vogel, Bewegung (wie Anm. 2), S. 42; Huber, Verfassungsgeschichte (wie Anm. 2), S. 79.

45 Zum zunehmenden Verlust der Landsässigkeit vor allem altadliger sächsischer Familien, die somit auf andere Strategien des Obenbleibens, mithin andere Tätigkeitsfelder angewiesen waren: JosEF MATZERATH, Adelsprobe an der Moderne. Sächsischer Adel 1763 bis 1866. Entkonkretisierung einer traditionalen Sozialformation (Vierteljahresschrift für Sozial- und Wirtschaftsgeschichte, Beihefte 183), Stuttgart 2006, S. 254-258. Angehörige des Militärs, ein weiteres Betätigungsfeld des Adels im 19. Jahrhundert, ließen sich mit Beiträgen zur Reformdiskussion nicht nachweisen.

46 VOGEL, Bewegung (wie Anm. 2), S. 42.

47 Ebd., S. 44.

48 Zusammengefasst wiedergegeben bei SCHMIDT, Staatsreform (wie Anm. 6), S. 316318.

49 Über ihn Georg MÜller, Eduard von Wietersheim, in: Allgemeine Deutsche Biographie, Bd. 55, hrsg. von der Bayerischen Akademie der Wissenschaften, Leipzig 1910, S. 72-89; CÄsAR Dietrich vON WitZlebBen, Eduard von Wietersheim, Leipzig 1865. Wietersheim war in den Freiheitskriegen wie Wilhelm Traugott Krug und andere Freiwillige im Banner der Freiwilligen Sachsen. 
ging in einer 1830 verfassten Denkschrift davon aus, dass Sachsens Wohl und Wehe eng mit dem ökonomischen Fortschritt, mit Handel und Fabrikwesen verbunden sei. ${ }^{50}$ In einer Schrift über die Hebung und Unterstützung des Fabrikwesens von 1827 forderte er angesichts der von ihm durch Erhebungen in verschiedenen Landesteilen Sachsens festgestellten Hemmnisse staatliche Unterstützung des Fabrikwesens und die Befreiung vom Innungszwang, also Freihandel und Wettbewerb. ${ }^{51}$ Es zeigen sich deutlich wirtschaftsliberale Züge, jedoch keine theoretischen Grundlegungen, die ihn einer bestimmten Schule zuordnen ließen. ${ }^{52}$ Carl Heinrich Freiherr von Teubern, ${ }^{53}$ ein aus einer 1734 geadelten Familie stammender Freimaurer, gehörte nicht dem Landtag von 1830 an. Teubern durchlief nach einem Jurastudium in Wittenberg eine glänzende Karriere im Staatsdienst. Seit 1830 war er Präsident des Appellationsgerichts. Auf eine Anfrage der Stände und des Geheimen Rats legte Teubern im Juli 1830 ein Gutachten ${ }^{54}$ über eine Justizreform vor. Er schlug eine grundlegende, noch nie da gewesene Umgestaltung der Justiz vor. Sein Gutachten sah eine Trennung von Justiz und Verwaltung sowie eine gründliche Reform der gesamten Gerichtsverfassung vor. Sämtliche Gerichte sollten staatlich sein. Ein geordneter Instanzenzug über drei Instanzen $\mathrm{zu}$ einem einzigen Obergericht wurde gefordert, insbesondere um die Rechtseinheit im Lande zu gewährleisten. Die Justizaufsicht war nach Teuberns Meinung von einem Justizministerium als oberste Staatsbehörde zu führen. Diesem sollten auch Stellenbesetzung und Justizprüfung obliegen. 55 Teubern kritisierte die bestehenden Verhältnisse aus der Perspektive der Justiz. Darauf beschränkten sich denn seine äußerst wichtigen, stark zukunftsweisenden Vorschläge, die sich in $\mathbb{S}$ 45-55 der Verfassung von 1831 widerspiegeln sollten. Auch seinem Beitrag liegen rein praktische Erwägungen zugrunde, ohne dass er erkennbar einer bestimmten Schule angehörte.

Rechte und Ausgestaltung der Volksvertretung in einer konstitutionellen Monarchie indes waren Gegenstand zweier noch vor den Septemberunruhen des Jahres 1830 erschienener Mahnungen an König und Landtag der bereits genannten Albert von Carlowitz und Otto Friedrich Heinrich von Watzdorf, die wie Salza als junge Beamte bei der Landesregierung in Dresden, dem regelmäßigen Ausgangspunkt großer Karrieren im sächsischen Zivilstaat, Dienst taten, jedoch anders als jener - zugleich Mitglieder des Landtags waren. Carlowitz, der sich unter dem Pseudonym Alwin von Candia als Dichter einen Namen machte, studierte wie Salza, der ebenfalls dichtete, und Watzdorf in den 1820er-Jahren Jura an der Universität Leipzig, um 1826 zum Assessor bei der Landesregierung in Dresden ernannt zu werden. Auch nach 1831 blieb er mit kurzer freiwilliger

50 Zitiert nach MüLleR, Wietersheim (wie Anm. 49), S. 72 f.

$51 \mathrm{Zu}$ seinen Denkschriften näher SCHLECHTE, Vorgeschichte (wie Anm. 8), S. 49-51.

52 Näher SCHMidT, Staatsreform (wie Anm. 6), S. 102.

53 Über ihn ebd., S. 295, Anm. 54.

54 Nicht veröffentlicht; Nachweis der Fundstelle ebd., S. 294, Anm. 52.

55 Näher ebd., S. 294-298. 
Unterbrechung im Staatsdienst, machte daneben aber als Landtagsmitglied und Politiker Karriere. In den 1830er- und 40er-Jahren war er der Wortführer der konservativen Vertreter in der sächsischen ersten Kammer. ${ }^{56}$ Carlowitz veröffentlichte bereits im November 1829 anonym in der Zeitschrift „Biene“ eine Adresse des sächsischen Volkes an seinen gütigen und geliebten König bei Eröffnung des Landtages, in der er sich für eine Repräsentativ-Verfassung, für Verantwortlichkeit der Minister gegenüber dem Volk und für mittelbaren Einfluß auf die wichtigsten Angelegenheiten und Beschlïsse des Staats durch echte Volksrepräsentanten und eine gleichmäßige Verteilung der öffentlichen Lasten unter die privilegierte und nicht privilegierte Klasse der Gesellschaft einsetzte. ${ }^{57}$ Dabei forderte Carlowitz eine Volksvertretung, bestehend aus Vertretern sämtlicher Stände des Königreichs, aus Lebr- und Wehr- und Nährstand, aus Vertretern des Adels, des Bürgertums und des Bauernstands, die ein rundes sich fröblich um seine Achse bewegendes Ganze[s] bildeten, [m]annigfach emsig und verschieden geschäftig in den Zeiten der Rube, aber einig, wo es der Anstrengungen Aller für das Ganze bedarf, bei den Versammlungen wirklich so zu nennender Volksvertreter [...] im Kampfe für Vaterlands-Freibeit und den Rubm seines hochsinnigen Fürsten. ${ }^{58}$ Muhs weist zu Recht darauf hin, dass Carlowitz die Verfassung des Großherzogtums SachsenWeimar-Eisenach von 1816, die maßgeblich von den naturrechtlichen Vorstellungen des herrnhutisch erzogenen großherzoglich sächsischen Geheimen Assistenzrats Ernst August von Gersdorff beeinflusst war, hervorhob. ${ }^{59}$ Hieraus folgert Muhs, dass sich Carlowitz damit in der Nähe des einerseits protestantisch-pietistisch und historisch-organisch, andererseits auch vernunftrechtlich beeinflussten süddeutschen Liberalismus bewegt habe. ${ }^{60}$

Jedoch war es nicht allein die weimarische Verfassung, sondern es waren auch die der Königreiche Bayern und Württemberg, die Carlowitz im selben Atemzug nannte. Ihnen allen schaute er ausdrücklich nur die durch das RepräsentativSystem modificirte Regierungsform ab. Weitere Hinweise insbesondere auf vernunftrechtlich begründete Besonderheiten der Verfassung Weimars unterbleiben.

56 Über ihn Josef Matzerath, Albert von Carlowitz, in: Sächsische Biografie (wie Anm. 12) (Zugriff 11. Juni 2012).

57 AlBeRT VON CARLOWITZ, Adresse des sächsischen Volkes an seinen gütigen und geliebten König bei Eröffnung des Landtages, in: Die Biene. Wöchentliche Mittheilungen für Sachsen und angrenzende Länder 1829, Nr. 46, S. 361-367, hier S. 363, 365.

58 Ebd., S. 367.

59 Ebd., S. 363.

60 Zur Einordnung von Carlowitz' Entwurf Murs, Liberalismus (wie Anm. 2), S. 210; REINHARDT, Unruhen (wie Anm. 2), S. 58 f. Zur Verfassung des Großherzogtums SachsenWeimar-Eisenach TRAUGOTT JÄHNICHEN/NORBERT FRIEDRICH, Von den Befreiungskriegen zur Errichtung des Deutschen Reichs. Der Protestantismus und der Beginn der modernen Verfassungsgeschichte in Deutschland, in: Günter Brakelmann/Norbert Friedrich/ Traugott Jähnichen (Hg.), Auf dem Weg zum Grundgesetz. Beiträge zum Verfassungsverständnis des neuzeitlichen Protestantismus, Münster 1999, S. 30-45, hier S. 31 f. Über den vernunftrechtlichen und den süddeutschen Liberalismus in seinen verschiedenen Schattierungen STOLLEIS, Geschichte (wie Anm. 7), S. 159-179. 
Vielmehr fährt er fort: Den ersten Schritt in einer so bochwichtigen Sache [der Einführung der genannten Regierungsform - HvS] zu thun, kann, unbesorgt um mögliche Nachtheile, nur der Fürst sich entschließen, der, gewohnt nach den ewigen Gesetzen des Rechts und der Billigkeit, frei von Leidenschaftlichkeit und andern unlautern Beweggründen sein Volk zu regieren, auf die Ebrlichkeit und Liebe der Gesammtheit seiner Unterthanen rechnen darf. 61 Carlowitz erscheint gerade nicht als Verfechter der Idee, einen Staat auf völlig neuer Grundlage, etwa auf der eines Staatsvertrags zwischen König und Volk, den die Vernunftrechtler forderten, zu schaffen. Vielmehr hat ihm zufolge allein der König das Recht, einseitig das Rechtsverhältnis mit dem Volk auf Grundlage des überkommenen Rechts zu verändern, besser: fortzuentwickeln. An den Beginn seiner Ausführungen setzt Carlowitz Worte Herders aus „Tithon und Aurora“: Nicht nur einzelne Personen, [...] sondern auch sogenannte politisch moralische Personen, Einrichtungen und Stände überleben sich. Was nicht dem Genius der Meinungen zu folgen, und sich mit ibm zu verjüngen weiß, bleibt entweder am Ufer des Zeitenstroms liegen, oder der Strom trägt es seelenlos fort [...]. Was geboren wurde, muß sterben, und was durch Kunstmittel seinen Hingang aufhäl, hat sich, indem es bierzu greift, schon selbst überlebt. ${ }^{62}$ Herder, für den das Recht wie Sprache und Religion als Kulturphänomen nur in seiner historischen Genese erklärbar und entwickelbar war, gilt als maßgeblicher Ideengeber für die Väter der Historischen Rechtsschule. ${ }^{63}$ Die von Carlowitz zitierten Passagen lassen Verfassungsstrukturen als Organismus erscheinen, der entsteht, sich unaufhaltsam entwickelt und abstirbt. Dabei hat er ausschließlich die Geschichte der Völker deutscher Zunge $e^{64}$ im Blick. Carlowitz erweist sich damit als Vertreter der - wohl germanistischen - Historischen Rechtsschule.

Otto Friedrich Heinrich von Watzdorf studierte ebenfalls in den 1820er-Jahren an der Universität Leipzig Jura. Neben seiner Stellung als Beamter bei der Landesregierung, die er wie die vorgenannten Carlowitz und Salza seit 1826 bekleidete, war er als Rittergutsbesitzer Mitglied des letzten vorkonstitutionellen Landtags. Watzdorf gehörte ab 1839 dem liberalen, später radikal linken Hallgartenkreis an und war Mitglied des Frankfurter Vorparlaments und der Nationalversammlung, wo er sich für eine republikanische Verfassung nach Vorbild der Vereinigten Staaten einsetzte. ${ }^{65}$ Indes äußerte er sich in der aus dem Jahr 1830 stammenden Schrift „Ueber die Nothwendigkeit einer Veränderung der im Königreich Sachsen der-

61 Carlowitz, Adresse (wie Anm. 57), S. 363.

62 Ebd., S. 361 f.

63 Franz WIEACKer, Privatrechtsgeschichte der Neuzeit: unter besonderer Berücksichtigung der deutschen Entwicklung, Nachdruck der 2. Auflage von 1967, Göttingen 1996, S. 355 f.; vgl. bereits VICTOR EHRENBERG, Herders Bedeutung für die Rechtswissenschaft, Göttingen 1903, S. 7, 17.

64 CARlowitz, Adresse (wie Anm. 57), S. 362.

65 Über ihn ThORSTEN TONNDORF, Die sächsischen Abgeordneten der Frankfurter Vor- und Nationalversammlung, Diss. Dresden 1993, S. 255 f. 
malen bestehenden ständischen Verfassung "66, mit welcher er ausdrücklich nicht bezweckte, einen vollständigen Entwurf zu einer nenen Verfassung zu liefern, ${ }^{67}$ gemäßigter. Watzdorf stellte fest, dass die bisherige ständische Verfassung nicht alle Stände, vor allem nicht die Bauern auf dem Lande und die nicht ratsfähigen Bürger und Einwohner der Städte berücksichtige, und nahm sich insbesondere das insoweit fortschrittliche Zwei-Kammer-Modell Englands zum Vorbild: Nach dem Beispiele Großbritanniens haben die meisten aufgeklärten Staaten Europas dem Grundsatze gehuldigt, daß jene Mischung des monarchischen, aristokratischen und demokratischen Prinzips, welche man gewöhnlich mit dem Namen des Repräsentativ-Systems bezeichnet, am meisten dazu geeignet sei, den staatsrechtlichen Bedürfnissen unserer Zeit zu entsprechen. [...] Diese Einrichtung hat den Vortheil, daß alle Stände [...] einen ibrem Interesse entsprechenden Einflu $\beta$ auf die gesetzgebende Gewalt des Staates ausüben. ${ }^{68}$ Watzdorf erscheint stark von Montesquieu beeinflusst, indem er fordert: Die Gewalt des Staates zerfällt in die gesetzgebende, richterliche und vollziehende. ${ }^{69}$ Dabei forderte er jedoch keineswegs, wie in der Literatur behauptet, ${ }^{70}$ das ausschließliche Gesetzesinitiativrecht der Volksvertretung, das vielmehr auch ihm zufolge weiterhin beim König verbleiben sollte.71

Dies und seine Hinwendung zum englischen Parlamentarismus könnte Watzdorf auf den ersten Blick als Anhänger der historisch-organischen Linie, mithin der Historischen Rechtsschule zu erkennen geben. Jedoch weisen die Überlegungen, mit denen er nach einer Rechtsgrundlage für eine Staatsreform sucht, in eine andere Richtung: Schlïßlich verdient noch die Frage, auf welche Art eine Veränderung der bestehenden Verfassung zu bewirken sei? mit einigen Worten erörtert zu werden. Jede Staatsgewalt ist aus einem ausdrücklichen oder stillschweigenden Vertrage abzuleiten, welcher in Monarchien zwischen den Regenten und den Unterthanen, in Republiken zwischen allen Staatsbürgern unter einander besteht. Da nun nach rechtlichen Grundsätzen ein vertragsmäßiges Verbältniß nur mit gegenseitiger Einwilligung der Contrabenten abgeändert werden darf, so folgt hieraus von selbst, daß die Umgestaltung der in einem Staate geltenden Verfassung auf dieselbe Weise zu bewirken ist. Wenn daher in Sachsen der Entwurf einer neuen Verfassung nur von der Weisheit des Regenten ausgeben kann, so erfordert es auf der anderen Seite die Gerechtigkeit, nicht nur den Landständen eine berathende Stimme dabei einzuräumen, sondern auch die Annabme derselben von

66 OtTo Friedrich Heinrich von Watzdorf, Ueber die Nothwendigkeit einer Veränderung der im Königreich Sachsen dermalen bestehenden ständischen Verfassung, Dresden 1830 .

67 Ebd., S. 11.

68 Ebd., S. 2 f.

69 Ebd., S. 12.

70 Vgl. Muhs, Liberalismus (wie Anm. 2), S. 209 f.; Vogel, Bewegung (wie Anm. 2), S. 41; REINHARDT, Unruhen (wie Anm. 8), S. 59 f.

71 WATZDORF, Nothwendigkeit (wie Anm. 66), S. 12. Das Gesetzesinitiativrecht war auch gemäß $\ 85$ Abs. 1 der Sächsischen Verfassung von 1831 ausschließlich dem König vorbehalten. 
ibrer Einwilligung abbängig zu machen. ${ }^{72}$ Watzdorf offenbart sich damit im Gegensatz etwa zu Carlowitz klar als Vertreter der vernunftrechtlichen Lehre von der voluntaristischen, konsensualen und rationalistischen Begründung der Staatsgewalt auf Grundlage eines fiktiven Vertrags freier Menschen. Die Historische Rechtsschule lehnte diesen Ansatz von ihrem Standpunkt einer historisch-organischen Entwicklung jeden Gemeinwesens aus als künstlich ab. Dieser Ansatz, der das Rechtsverhältnis zwischen König und Volk auf eine von den gewachsenen Strukturen völlig abweichende, nämlich auf eine gleichermaßen von beiden im Rahmen eines Gleichordnungsverhältnisses neu geschaffene Rechtsgrundlage stellte, mag der Grund dafür gewesen sein, dass der Schrift von der Regierung das Imprimatur verweigert wurde.

Angesichts der Septemberunruhen meldeten sich jetzt auch wieder Vertreter des Bürgertums mit Vorschlägen insbesondere hinsichtlich der Beteiligung an der Volksvertretung zu Wort. So forderte am 12. September 1830 die Dresdner Bürgerschaft mit einer durch Christian Gottlob Eisenstuck ${ }^{73}$ verfassten Schrift die Einberufung der Landstände, in die fortan auch Vertreter des Bürger- und Bauerntums gewählt werden sollten. ${ }^{74}$ Langsam und gerüchteweise wurde nun auch bekannt, König und Regierung planten, dem auf März 1831 vertagten Landtag einen Verfassungsentwurf vorzulegen. Dies führte zu einer wahren Flut von kleineren Schriften aus dem bürgerlichen Lager. ${ }^{75}$ Bemerkenswert ist insoweit ein Verfassungsentwurf unter dem Titel „Constitution, wie sie das sächsische Volk wünscht",76 der erst vorgelegt wurde, nachdem der Landtag seine 1830 unterbrochenen Verhandlungen am 1. März 1831 wieder aufgenommen hatte. Er stammte vom revolutionären Dresdner „Bürgerverein“ unter Führung des jakobinisch beeinflussten Rechtsanwalts Bernhard Moßdorf77 und enthielt acht Abschnitte mit 133 Paragrafen, die - die französischen und belgischen Verfassungen zum Vorbild - vorsahen, sämtliche Adelsvorrechte und Titel abzuschaffen, lediglich eine Kammer des Landtags zu schaffen und dem König, der gegen Gesetzesbeschlüsse des Landtags nur ein suspensives Vetorecht haben sollte, nur die vollziehende Gewalt zuzubilligen. Die Verfassung war überschrieben mit dem Motto: „Und wird sie nicht gewährt, so pochen wir mit Flintenkolben an. "78 Damit hatten sich Moßdorf und sein Bürgerverein von vornherein für einen revolutionären Weg entschieden. Ein ernsthafter Diskurs war offenbar nicht gewollt. Der Entwurf hatte nach Kon-

72 Watzdorf, Nothwendigkeit (wie Anm. 66), S. 16 f.

73 Über ihn HeInRICH THEOdOR Flathe, Christian Gottlob Eisenstuck, in: Allgemeine Deutsche Biographie, Bd. 5, hrsg. von der Bayerischen Akademie der Wissenschaften, Leipzig 1877, S. 775.

74 SCHMIDT, Staatsreform (wie Anm. 6), S. 105.

75 Übersicht bei EICHSTÄDT, Publizistik (wie Anm. 8), S. 57-62.

76 Bernhard Mossdorf, Constitution, wie sie das sächsische Volk wünscht, o. O. 1831.

77 Über ihn SCHMIDT, Staatsreform (wie Anm. 6), S. 107, insbes. Anm. 27.

78 Mossdorf, Constitution (wie Anm. 76), S. 6. 
rad Krause letztlich nur den Sinn, „der zögerlichen staatlichen Reformpolitik eine revolutionäre Kraft entgegenzustellen“. ${ }^{79}$

\section{$V I$.}

Mit Carl von Salza und Lichtenau schaltete sich im Jahr 1830 an der Stelle der Debatte, als bekannt wurde, dem Landtag werde von der Regierung ein Verfassungsentwurf vorgelegt werden, lediglich ein einziger Beamter des höheren Staatsdienstes und Angehöriger des sächsischen Adels ein. Anders als alle übrigen Beiträge zur Reformdiskussion stellte seine 1830 erschienene, eingangs genannte Schrift „Ueber die künftige ständische Verfassung Sachsens. Eine Stimme zu dem bevorstehenden Landtage" zudem insbesondere im Hinblick auf die beiden bekannten Entwürfe der Regierungsmitglieder Hans Georg von Carlowitz ${ }^{80}$ und Bernhard August von Lindenau ${ }^{81}$, die 1831 zusammen mit dem Verfassungsentwurf82 der Regierung in den Landtag eingebracht wurden und unmittelbar zur Verfassung von 1831 führten, den ersten eigenständigen, wenn auch außerparlamentarischen Entwurf einer sächsischen Verfassung und eben nicht lediglich eine der vielen bislang bekannt gewordenen Aufsätze dar. Ein anonym Gebliebener ließ um dieselbe Zeit lediglich die badische Verfassung ohne Änderungen abdrucken und in Sachsen verbreiten, ${ }^{83}$ und der bereits genannte Entwurf Moßdorfs erschien erst während der Landtagsverhandlungen. Die Gründe, warum auf den Salzaschen Vorschlag im Folgenden näher eingegangen wird, sind jedoch inhaltlicher Natur.

Bereits in seinem „Handbuch des Polizeirechts“ von 1825, einer rein juristischen Veröffentlichung, äußert sich der erst 23-jährige Carl von Salza und Lichtenau über seine Methode: Die Eintheilungen [die Gliederung des Buchs - HvS], welche sich aus der Natur der Sache ergaben, werden hoffentlich ungezwungen und zweckmäßig erscheinen. ${ }^{84}$ Seiner Arbeit setzt er eine geschichtliche Darstellung der Entstebung und der Ausbildung der Polizei voran, auf die er im weiteren Verlauf immer wieder zurückgreift. Salza geht davon aus, dass es erst zu fränkischer Zeit wichtigere Polizeiverfügungen gegeben habe. Durch das Absinken des Fränkischen Reichs sei die hier gewonnene allgemeine Sicherbeit gefäbrdet wor-

79 Konrad Krause, Alma Mater Lipsiensis. Geschichte der Universität Leipzig von 1409 bis zur Gegenwart, Leipzig 2003, S. 112.

80 Über ihn Herta BatTRÉ, Hans Georg von Carlowitz, in: Neue Deutsche Biographie, Bd. 3, hrsg. von der Bayerischen Akademie der Wissenschaften, Berlin 1957, S. 147; sein Entwurf abgedruckt WiTZLEBEN, Entstehung (wie Anm. 8), Beilage 6, S. 330-357.

81 Über ihn Oliver Werner, Bernhard August von Lindenau, in: Sächsische Biografie (wie Anm. 12) (Zugriff 11. Juni 2012); sein Entwurf abgedruckt WitZlebEN, Entstehung (wie Anm. 8), S. 357-369.

82 Abgedruckt Witzleben, Entstehung (wie Anm. 8), Beilage 7, S. 370-401.

83 ANONYmus, Die Staatsverfassung des Großherzogthums Baden, o. O., o. J.

84 SAlZA, Polizeirecht (wie Anm. 15), S. VIII. 
den. Die noch im Mittelalter insbesondere durch die Entstehung von Stadt und Stadtrecht geförderte zweckmäßige Polizei sei durch Polizeiordnungen ab dem 15. und 16. Jahrhundert, die größtentheils auf falschen Ansichten beruht hätten und überhaupt mit unendlich vielen fremdartigen Bestimmungen verwischt gewesen seien, beeinträchtigt worden. Diese hätten nicht beigetragen, das wabre Wesen der Polizeigewalt festzusetzen. Erst im Frankreich Ludwigs XIV. sei es zu zweckmäßigeren Polizeieinrichtungen gekommen. Die Schrecknisse der gebeimen Polizei, welche sich wäbrend der französischen Oberherrschaft in Deutschland in einzelnen Staaten zeigten, sind mit dem Fall Napoleons verschwunden. ${ }^{85}$ Vor allem theoretische Verfremdung des Begriffs der Polizei ab dem 15. Jahrhundert hätte zu nachteiligen praktischen Folgen geführt: Diese Irrtbümer der Theoretiker gingen in's Leben über und öffneten Willkür eine weite Babn. Unerträgliche Beschränkungen, unnütze und beschwerliche Vorschriften erzengten die größten Nachtheile im Inneren der Staaten, und machten das Institut verhaßt, das zweckmäßig organisiert, so wesentlich zur allgemeinen Woblfahrt eines Volkes beiträgt. ${ }^{86}$ Bereits diese Zeilen zu Beginn des Werks lassen Salzas juristische Methode deutlich werden: Er verlangt zweckmäßiges Recht und geht davon aus, dass sich dieses nicht etwa durch theoretische Konstruktionen, sondern allein durch die Betrachtung der natürlichen Zustände und Entwicklungen erkennen lässt. Er lehnt aufgezwungenes Recht ab, wie der Verweis auf die napoleonische Herrschaft in Deutschland zeigt. Er fordert die Rückbesinnung auf vorrevolutionäres beziehungsweise heimisches Recht, insbesondere auf das frühe und hohe deutsche Mittelalter, dessen wabres Wesen durch die Einführung fremdartigen, also wohl rezipierten Rechts und dessen Auslegung durch Theoretiker, also wohl Gelehrte im Gegensatz zu (Laien-)Vertretern aus dem Volk selbst, überlagert sei. Bereits diese Ausführungen lassen Carl von Salza mithin als Vertreter der germanistischen Historischen Rechtsschule erscheinen.

$\mathrm{Ob}$ und wie sich dies auf Salzas staatstheoretische Überlegungen auswirkte, ergibt sich aus den umfangreichen Kommentierungen zu seinem Verfassungsentwurf von 1830. Bereits auf dem Vorsatz der Schrift findet sich folgendes Zitat Ernst Moritz Arndts: Auch diese besten Staaten können sich ableben und vor Alter sterben, wann das Zeitalter oder der Muth feblen, das Versteinerte oder Verknöcherte, worin der Tod sitzt, wegzuräumen, oder wann dem Volke die Kraft fehlt, das Harte wieder weich und das Dürre und Welke wieder grün und saftig zu machen. Auch seine hiesigen Ausführungen lässt Carl von Salza mit einem tiefen Blick in die Geschichte beginnen: Die vielbewegte Zeit hat auch uns ergriffen! [...] Die Stimme des Volks ist bis zum Throne gedrungen - beachtet, erbört zu werden! [...] Laßt uns daber einen prüfenden Blick in die Vergangenheit werfen, auf daß wir schanen, was wir waren und was wir werden sollen. - Die strenge Richterin, welche unser vergangenes Leben aufzeichnete, sey nicht umsonst befragt. Sie sey

85 SAlZA, Verfassung (wie Anm. 11), S. $11 \mathrm{f}$.

86 Ebd., S. 27. 
der Polarstern, den wir nicht aus den Augen verlieren, der Compaß, den wir auf unserer neuen politischen Laufbabn zu Rathe ziehen wollen, damit es uns gelinge, die Klippen zu umschiffen, an denen wir so oft scheiterten. [...] Es ist wahr, der forschende Patriot kann nur mit wehmütigen Gefüblen die Blätter der vaterländischen Geschichte aufschlagen, nur mit trüben Augen in eine Vergangenheit blicken, so groß und glorreich bei ibrem Beginnen, so niederschlagend und vernichtend in ibrer Folge. Wir können uns die traurige Wabrheit nicht verbergen, wir gleichen einer Pflanze, die frübzeitig blübte und Früchte trug, nun aber verwelkt dastebt, mitten unter den üppigen Gewächsen des verjüngten Europa. Eine andere, glorreichere Zukunft schien den Sachsen zu leuchten [...]. Wir wurden die Leuchte in der Finsterni $\beta$, die allen Völkern das Licht der Wabrheit sandte! Wir wurden die Vorfechter im heiligen Kampfe des Glaubens [Bezugnahme auf die Reformation HvS], als die weisen Fürsten unseres Stammes, dem Geiste des Volkes vertranend, die ernste Mahnung der Zeit erkannten. ${ }^{87}$ Bereits diese Ausführungen zeigen, dass Carl von Salza auch seine staatstheoretischen Vorschläge auf eine historisch-organische Sicht gründet. Er möchte anhand der von ihm als glorreich geschilderten älteren sächsischen Geschichte nachweisen, dass gerade in Sachsen im Zusammenwirken von Fürst und Volk ursprünglich Großartiges habe geleistet werden können. Gerade hier habe bereits im Mittelalter ein harmonischer Ausgleich zwischen Herrscher und Volk bestanden, indem die Herrscher bei ihrer Regierung die Bedürfnisse des Volkes erkannt und berücksichtigt hätten. Salza geht von einem Geist des Volkes aus, also mithin von einem dem gesamten sächsischen Volk innewohnenden gemeinsamen Geist, den die sächsischen Fürsten erkannt und erhört hätten.

Salza fährt mit den historischen Betrachtungen fort, wobei er nun auf das 18. Jahrhundert zu sprechen kommt: Die Amtszeiten Fürstenbergs und Brühls hätten jede Spur eines gediegnen, selbstständigen Volkscharacters [...] verwischt. [...] Als halbe Maßregeln an die Stelle der Kraft und Entschlossenheit traten, ein zweideutiges Hin- und Herschwanken für Staatsklugheit gelten sollte, und dieses System von nun an die Weisheit unsrer Politik blieb, so börte die Bedeutung auf, die der Name Sachsen im Reiche, im Auslande genossen hatte. [...] Eine zerstückelte, abgerissene, schwülstige Gesetzgebung voller Widersprüche und Zweidentigkeiten, eine geheimnisvolle lichtscheue Ängstlichkeit in allen Zweigen der Verwaltung, die unpassendste Zusammenstellung des Alten und Neuen, wiederholte Verstöße gegen den Geist der Zeit und ein unbegreifliches Nichtbeachten aller Bedürfnisse, die sich im Volke laut offenbarten. So mußte denn Alles erstarren, was in unsere Nähe kam, jede Spur des treibenden Lebensprinzips aus unsrer Mitte verschwinden, wir mußten stumpf werden selbst für die Worte: Vaterland, Freiheit! Salza sieht also den ursprünglichen, glücklichen harmonischen Zustand Sachsens abgelöst von einer Zeit des Zerfalls, der sich insbesondere darin ausdrücke, dass die Regierung nicht mehr in der Lage beziehungsweise willens gewesen sei, den sächsischen Volkscha-

87 Ebd., S. 3-5. 
rakter, den Geist der Zeit zu erkennen und zu beachten. Stattdessen habe eine abgehobene, mithin notwendig unzureichende und widersprüchliche Gesetzgebung und eine das Volk scheuende Verwaltung Platz gegriffen. Das Auseinanderfallen von Volksgeist und Regierung durch die Missachtung der in Sachsen überkommenen Kultur des Ausgleichs zwischen Monarch und Volk habe Sachsen neben dem Zerfall im Inneren vor allem auch seinen herausgehobenen Platz unter den Staaten Europas gekostet.

Die an die eben zitierten Passagen anschließenden Überlegungen Salzas beziehen sich auf das 19. Jahrhundert: Endlich übernahm Friedrich August [I. - HvS] die Zügel der Regierung [...]. Manche Veränderung, manche Verbesserung, manche neue organische Einrichtung wurde mit Schonung, Umsicht und Weisheit ausgeführt. Aber die politischen Stürme, die zu Ende des vorigen Jabrbunderts ausbrachen [Französische Revolution - HvS], drängten auch hier, wie überall das aufkeimende Leben zurück. Die traurige Wendung, welche die Staatsumwälzung in Frankreich nabm und dieses Reich an den Abgrund des Verderbens fübrte, warnte vor einer gefäbrlichen Neurungssucht, die sich aller Gemüther bemächtigt hatte [...]. Es galt, mit sorgender Wachsamkeit das Bestehende zu erhalten, das Veraltete der neuen Zeit anzupassen. Die persönliche Würde des Monarchen habe zur Zeit der napoleonischen Herrschaft und Kriege allzu großen französischen Einfluss auf das Innere Sachsens verhindern können. Salza möchte nun herausstellen, dass die sächsischen Fürsten auch weiterhin um schonende, die organische Entwicklung im Volk berücksichtigende Regierung bemüht gewesen seien. Aber die Folgen der Französischen Revolution hätten dieses organische, nach Jahren des Verfalls im 18. Jahrhundert aufkeimende Leben behindert. Auch unter diesen Umständen sei der sächsische Landesherr aber bestrebt gewesen, nicht mit der gefährlichen Neurungssucht der Revolutionäre, sondern sorgsam, also angepasst an die organische Entwicklung Reformbedürftiges zu reformieren.

Mit Blick auf Sachsen im Jahr 1815 fragt Salza: Was konnte das politische Leben einer geschichtlich so tief gesunkenen Nation mehr seyn, als eine kümmerliche Vegetation? Was konnte unsere Gesetzgebung leisten, da sie nicht von dem Bedürfnisse des Volkes ausging? Er antwortet selbst: Doch lassen wir das Vergangene! Ein frischer jugendlicher Geist beginnt sich unter uns zu regen! Auch uns ist, wie Franzosen, Engländern, Preußen u. a. das Wobl des Vaterlandes eine hohe, hebre Angelegenheit geworden. Wir füblen die heiligen Pflichten, zu denen wir als Staatsbürger berufen sind! Und das ist die wichtige Aufgabe, die wir zu lösen haben, diesen Geist zu erbalten und zu pflegen! Wodurch könnte dieß aber bewirkt werden, als durch eine zweckmäßige Volksvertretung? Sie allein ist im Stande, eine geistige Wechselwirkung zwischen dem Landesfürsten und der Nation zu unterhalten und um beide ein Band des Vertrauens zu schlingen, welches stark genug ist, allen Stürmen der Zeit zu trotzen! Oder was wäre geeigneter, die Bedürfnisse des Volks zur Kenntniß der Regierung zu bringen; die Nation wider das willkürliche Schalten und Walten eigennütziger, beschränkter und engherziger Staatsdiener zu sichern? Da wird die Krone die sicherste Bürgschaft unwandel- 
barer Liebe, Trene und Anhänglichkeit finden, wo sie statt bezablter Beamten, die ibrem Berufe leben müssen, die unabbängigen Repräsentanten aller Stände um sich versammelt. Aus dem Schooße dieser Versammlung werden die kräftigsten Stützen für Thron und Land hervorgehen, um auch nach Außen der Monarchie Achtung, Glanz und Selbstständigkeit zu sichern. Die abgestorbene ständische Verfassung, welche mit allen Vorurtheilen einer längst verblichenen Zeit, die kein Sterblicher wieder herauf beschwören wird, bis auf uns gekommen ist, kann diesen Zweck nicht erfüllen. Wir bedürfen einer neuen Verfassung, hierüber herrscht nur e in $e$ Stimme. Rings um uns ist eine im Kampfe erstarkte Jugend uns vorangeeilt. Es ist Zeit, daß auch wir unseren Stammgenossen im deutschen Reich folgen, daß wir unter ibnen wiederum eine ebrenvolle Stelle einnebmen!

Dieses Ende seiner Vorüberlegungen zeigt Carl von Salza in Zusammenschau mit den anderen bereits zitierten Passagen in einem weiteren Licht. Wie bereits angedeutet, gab er im Jahr 1847 mit „Abendsegen“ ein Gedicht aus dem Nachlass von Novalis heraus. ${ }^{88}$ Auch angesichts der staatstheoretischen Überlegungen scheint es, dass Salza - bereits in jungen Jahren - ein großer Anhänger von Novalis war. Wie dieser in seiner Europa-Rede glaubt Salza an eine glückliche Urzeit in Form des deutschen Mittelalters als der Zeit der Einheit aller Widersprüche, der Harmonie auch zwischen Herrscher und Volk, eine unerschütterliche Ordnung, die jedoch insbesondere durch die Folgen der Französischen Revolution grundlegend, gleichsam widernatürlich gegen alle organische Entwicklung verändert worden sei. Für die Wiederherstellung der ursprünglichen Harmonie, der geistigen Wechselwirkung zwischen dem Landesfürsten und der Nation, wie Carl von Salza es nennt, sei es jedoch jetzt an der Zeit. An die Stelle des complicirten, gebrechlichen und ungelenken Räderwerks trete die Einfachheit, die allbelebende Fülle und die fortbildende Kraft eines lebendigen Organismus! Dieser Satz macht es deutlich: Salza ging es nicht um eine künstliche Staatsmaschine, sondern um einen Staat, der sich gemäß der organischen Entwicklung seines Gemeinwesens selbst organisch weiterentwickelte. Ihm zufolge war es gerade Sachsen, dessen Geschichte zeige, dass ein Gemeinwesen ursprünglich durch harmonischen Ausgleich zwischen Volk und Monarch, der den Volksgeist erkenne, organisch geblübt habe. Diese Pflanze gelte es nun durch maßvolle Reform unter Berücksichtigung des Erhaltenswerten, aber auch unter Fortentwicklung des Bestehenden angepasst an die organische Weiterentwicklung des Gemeinwesens wiederzubeleben. Dies führe unmittelbar in einfache, klare, verständliche Gesetze: Wir haben den einfachen Grund unserer frühesten Verfassung und Verwaltung so stückweise, planlos erweitert; das jetzt eine chaotische Masse um uns liegt, die aufgeräumt seyn will, soll das Gute, Zweckmäßige, Geregelte Platz gewinnen. Carl von Salza ist danach klar der germanistischen Historischen Rechtsschule zuzuordnen. Er war ein Anhänger der Volksgeistlehre. Erkennbar war er romantisch, insbesondere von der Frühromantik Novalis' beeinflusst. Salza war Anhänger des Nationalstaats-

88 SAlZA, Carl von Salza (wie Anm. 12). 
gedankens, der sich nicht nur in seiner Befürwortung einer polnischen Nation zeigte, sondern auch bezogen auf Sachsen, das er - beseelt von einem Volksgeist als sein Vaterland ansah, und dass er in eine Reihe mit europäischen Staaten wie England und Frankreich stellte.

VII.

Carl von Salza setzte auf eine Verfassung, insbesondere auf eine in bestimmter Weise von dieser ausgestaltete Volksvertretung. Er schlug eine Verfassung vor, die im Wesentlichen der württembergischen vom 25. September $1819^{89}$ nachempfunden war. Wie diese enthält sein Verfassungsentwurf klassische liberale Forderungen wie nach Gleichheit aller Staatsbürger, nach gleichem Zugang zu allen Staatsämtern ohne Ansehung der Herkunft und nach einem Staatsgerichtshof, vor dem auch die Ministeranklage möglich war. Vor allem forderte Salza das verfassungsmäßige Recht auf Pressefreiheit. Dieses beinhaltet die Sächsische Verfassung von 1831 bekanntlich gerade nicht. Hinsichtlich der Ausgestaltung der Volksvertretung entwickelte Salza konkret auf die sächsischen Verhältnisse bezogene Vorschläge. Er ging von einem Zweikammersystem aus, in dem die bisherigen Stände die erste Kammer bildeten, also vor allem standesherrlicher und ritterschaftlicher Adel sowie die Vertreter bestimmter geistlicher Stifter und der Universitäten. (Sonstige) Vertreter des Bürgertums oder des Bauerntums waren nicht vorgesehen.

Die zweite Kammer sollte jedoch alle drei Stände berücksichtigen, die adelige Körperschaft eines jeden Kreises, die Vertreter der elf größten sächsischen Städte, die städtischen Kreiskörperschaften eines jeden Kreises und die Amtskörperschaften, bestehend aus den Vertretern der Dorfgemeinden eines amtshauptmannschaftlichen Kreises. Insoweit unterschied Salza jedoch jeweils nochmals nach Angesessenen und Unangesessenen. Also auch der unangesessene Adel, ein Phänomen bereits des 19. Jahrhunderts und dem auch Carl von Salza angehörte, sollte berücksichtigt werden, aber nur soweit die Familie altadlig, das heißt bereits seit 500 Jabren in sächsischen Landen bekannt war. Hinsichtlich der Angesessenen von Adel war der Besitz eines landtagsfähigen Ritterguts nötig. Insoweit ließ Salza indes auch bürgerliche Rittergutsbesitzer als Vertreter der adligen Körperschaft zu. Die angesessenen Vertreter der städtischen Körperschaften sollten im Besitz eines städtischen Grundstücks sein. Für Unangesessene sollte der wesentliche Aufenthalt in einer Stadt genügen, wobei die Ausschließung der Bedienten, Gesellen, Diener und Fremden sich von selbst versteb[e]. Entsprechendes sollte für die

89 Über diese und ihre Entstehung JOACHIM GERNER, Vorgeschichte und Entstehung der württembergischen Verfassung im Spiegel der Quellen (1815-1819) (Veröffentlichung der Gesellschaft für geschichtliche Landeskunde in Baden-Württemberg B/114), Stuttgart 1989; HARTWIG BRANDT, Parlamentarismus in Württemberg 1819-1870. Anatomie eines deutschen Landtags (Handbuch der Geschichte des deutschen Parlamentarismus), Düsseldorf 1987. 
Bauern bezogen auf Bauerngrundstücke beziehungsweise Dorfgemeinden gelten. Um als Unangesessener berücksichtigt zu werden, sollte die Errichtung einer mäßigen Steuerquote ausreichend sein.

Dies zeigt, dass Salza darauf bedacht war, alle Stände zu berücksichtigen. Seine Sichtweise war indes weiterhin stark ländlich-agrarisch geprägt. Die erste Kammer sollte nur die bisherigen Eliten, die weitgehend auf Landbesitz basierten, aufnehmen. Das in Sachsen eine nunmehr wesentliche soziale Gruppe darstellende handel- und gewerbetreibende Bürgertum wurde lediglich in der Weise berücksichtigt, dass von ihm ein landtagsfähiges Rittergut oder ein städtisches Grundstück gefordert wurde. Als eigenständige Gruppe sah Salza die Unternehmer jedoch nicht an. Es blieb auch ihm zufolge grundsätzlich beim Eigentum von Grund und Boden als Zugangsvoraussetzung. Einkommen in Geld spielten nach ihm nur bei den Unangesessenen als maßvolle Mindestvoraussetzung eine Rolle.

\section{VIII.}

Als Ergebnis ist festzuhalten: Zu Unrecht ist der Verfassungsentwurf, den Carl von Salza und Lichtenau 1830 veröffentlichte, in Vergessenheit geraten. Mit Salza meldete sich, kurz nachdem bekannt wurde, dass die Regierung einen Verfassungsentwurf in den Landtag einbringen werde, ein weiterer und an dieser Stelle der Reformdebatte einziger Angehöriger des sächsischen Adels zu Wort. Die Herren von Wietersheim, Freiherr von Teubern, von Carlowitz und von Watzdorf hatten sich bereits vor den Septemberunruhen in anderer Form geäußert. Anders als die genannten Reformer handelte es sich bei der Äußerung Carl von Salzas um einen ausformulierten, mit umfangreichen Kommentierungen versehenen Verfassungsentwurf, den ersten eigenständigen (außerparlamentarischen) überhaupt. Die Schrift deckt mithin eine Vielzahl von Themen ab, während die Vorgenannten lediglich in Aufsatzform zu einzelnen Themen Stellung nahmen, so etwa Teubern zur Gerichtsverfassung und Carlowitz und Watzdorf zur Volksvertretung. Mit Carlowitz und Watzdorf war Salza seit 1826 Assessor bei der Landesregierung in Dresden. Alle drei hatten zuvor ungefähr zeitgleich in Leipzig studiert. Es ist anzunehmen, dass sie sich gut kannten und miteinander auch über ihre Gedanken $\mathrm{zu}$ einer Staatsreform sprachen. Bei ihnen sind jeweils unterschiedliche staatstheoretische Grundlegungen erkennbar. Während Carlowitz der - wohl germanistischen - Historischen Rechtsschule zuzuordnen ist, war Watzdorf stark von vernunftrechtlichen Anschauungen beeinflusst. Salza ist dagegen und noch deutlicher als Carlowitz als - stark romantisch beeinflusster - Vertreter der germanistischen Historischen Rechtsschule und damit als gemäßigt liberaler Reformer anzusehen. Bei ihm ist der von Kern festgestellte Zusammenhang zwischen beidem klar zu erkennen. Salza ging es um den harmonischen Ausgleich zwischen Monarchie und Volk, wobei er aufgrund seiner stark historisch orientierten Herangehensweise bei der Ausgestaltung der Volksvertretung weiterhin das Bild einer ländlich-agrarisch 
geprägten Gesellschaft vor Augen hatte. Hier sollte $\mathbb{} 68$ Nr. 4 der Sächsischen Verfassung von 1831 moderner sein, indem eine eigene Gruppe der Vertreter des Handels und Fabrikwesens gebildet wurde, die Salza nicht berücksichtigte. Auch waren gemäß $\int 61$ Nrn. 15 f. die Städte in der ersten Kammer anders als in Salzas Entwurf berücksichtigt. Anders als es bisher gängige Meinung war, waren es nicht lediglich zwei Vertreter der jungen adligen Beamten des höheren Staatsdienstes, die die Reformdebatte 1829/30 wieder aufnahmen. Mit Carl von Salza und Lichtenau ist Albert von Carlowitz und Otto Friedrich Heinrich von Watzdorf ein weiterer Liberaler, der die Reformdebatte und damit letztlich die Staatsreform mit vorantrieb, an die Seite zu stellen.

\section{Anhang \\ Erstes Kapitel. \\ Von dem Königreiche.}

Sämmtliche Bestandtheile des Königreichs sind und bleiben $\mathrm{zu}$ einem unzertrennlichen Ganzen und zur Theilnahme an Einer und derselben Verfassung vereiniget. Das Königreich Sachsen ist ein Theil des deutschen Bundes; daher haben alle organische Beschlüsse der Bundesversammlung, welche die verfassungsmäßigen Verhältnisse Deutschlands oder die allgemeinen Verhältnisse deutscher Staatsbürger betreffen, nachdem sie von dem Könige verkündet sind, auch für Sachsen verbindende Kraft. Doch tritt in Ansehung der Mittel zur Erfüllung der hierdurch begründeten Verbindlichkeiten die verfassungsmäßige Mitwirkung der Stände ein.

\section{Zweites Kapitel. \\ Von dem Könige, der Thronfolge und der Reichsverwesung.}

Der König ist das Haupt des Staats, vereinigt in sich alle Rechte der Staatsgewalt, und übt sie unter den durch Verfassung festgesetzten Bestimmungen aus. Seine Person ist heilig und unverletztlich. Dieselben Attribute kommen dem Prinzen Mitregenten zu.

Das Recht der Thronfolge gebührt dem Mannsstamme des königlichen Hauses, die Ordnung desselben wird durch die Lineal-Erbfolge nach dem Erstgeburts-Rechte bestimmt. Erlöscht der Mannstamm, so geht die Thronfolge auf die herzoglich Ernestinische Linie des Hauses Sachsen über. Nach dem Aussterben des ganzen Sächsischen Hauses treten die Rechte des erbverbrüderten Hessischen ein.

Der König ist volljährig mit zurückgelegtem achtzehnten Jahre.

Der Huldigungseid wird von dem Thronfolger erst dann abgelegt, wenn er in einer den Ständen auszustellenden Urkunde die unverbrüchliche Festhaltung der Landesverfassung bei seinem königlichen Worte zugesichert hat.

Ist der König minderjährig oder aus einer andern Ursache an der eignen Ausübung der Regierung verhindert: so tritt eine Reichsverwesung ein, welche von dem nach der Erbfolge nächsten Agnaten geführt wird. 


\section{Drittes Kapitel. \\ Von den allgemeinen Rechtsverhältnissen der Staatsbürger.}

Das Staatsbürgerrecht wird theils durch Geburt, theils durch Aufnahme, theils durch Anstellung in dem Staatsdienste erworben.

Alle Sachsen haben gleiche staatsbürgerliche Rechte, und eben so sind sie zu gleichen staatsbürgerlichen Pflichten und gleicher Theilnahme an den Staatslasten verbunden.

Kein Staatsbürger kann wegen seiner Geburt von irgend einem Staatsamte ausgeschlossen werden.

Die Verpflichtung zur Vertheidigung des Vaterlandes und zum Waffendienste ist allgemein.

Der Staat sichert jedem Bürger Freiheit der Person, Gewissens- und Denkfreiheit, Freiheit des Eigenthums und Auswanderungsfreiheit.

Die Leibeigenschaft wird für immer aufgehoben.

Niemand darf seinem ordentlichen Richter entzogen, und anders, als in den durch Gesetz bestimmten Fällen, und in den gesetzlichen Formen verhaftet und bestraft, noch länger als 24 Stunden über die Ursache seiner Verhaftung in Ungewißheit gelassen werden.

Jeder, ohne Unterschied der Religion, genießt ungestörte Gewissensfreiheit; den vollen Genuß der staatsbürgerlichen Rechte gewähren die drei christlichen Glaubensbekenntnisse;

Die Freiheit der Presse und des Buchhandels findet in ihrem vollen Umfange statt; doch unter Beobachtung der gegen den Mißbrauch bestehenden oder künftig zu erlassenden Gesetze.

Jeder hat das Recht, über gesetz- und ordnungswidriges Verfahren einer Staatsbehörde, oder Verzögerung der Entscheidung, bei der unmittelbar vorgesetzten Stelle schriftliche Beschwerde zu erheben, und nöthigenfalls stufenweise bis zur höchsten Behörde zu verfolgen. Glaubt der Beschwerdeführer auch bei der Entscheidung der obersten Staatsbehörde sich nicht beruhigen zu können; so darf er die Beschwerde den Ständen mit der schriftlichen Bitte um Verwendung vortragen.

Der ritterschaftliche Adel bildet zum Behufe der Wahl seiner Abgeordneten in die Ständeversammlung und der Erhaltung seiner Familien, in jedem der fünf Kreise (die Oberlausitz als 5ter Kreis) eine Körperschaft.

Die Aufnahme in eine dieser Körperschaften hängt von ihrer Zustimmung und von der Genehmigung des Königs ab.

\section{Viertes Kapitel.}

Von den Staatsbehörden.

Niemand kann ein Staatsamt erhalten, ohne zuvor gesetzmäßig geprüft und für tüchtig erkannt zu seyn. Landeseingeborne sind, bei gleicher Tüchtigkeit, vorzugsweise vor Fremden zu berücksichtigen.

Alle von dem Könige ausgehende Verfügungen, welche die Staatsverwaltung betreffen, müssen von dem Minister oder Chef der betreffenden Behörde contrasignirt seyn, welcher dadurch für ihren Inhalt verantwortlich wird. Außerdem ist jeder Chef für dasjenige verantwortlich, was er für sich verfügt. Auf gleiche Weise sind auch die übrigen Staatsdiener und Behörden in ihrem Geschäftskreise verantwortlich.

Der geheime Rath bildet die oberste, unmittelbar unter dem Könige stehende und, seiner Hauptbestimmung nach, blos berathende Behörde. Mitglieder des geheimen Raths sind die Chefs des geheimen Finanz-Collegii, der Kriegsverwaltungs-Cammer 
und Landesregierung und diejenigen Räthe, welche der König dazu ernennen wird. In dazu geeigneten Fällen nehmen auch die Chefs des Oberconsistorii und des Obersteuer-Collegii an den Berathungen Antheil. Der König ernennt und entläßt die Mitglieder des geheimen Raths nach eigner freier Entschließung.

Alle dem Könige vorzulegende Vorschläge der Minister und obersten Behörden in wichtigen Angelegenheiten, namentlich in solchen, welche auf die Staatsverfassung, die Organisation der Behörden und die Abänderung der Territorialeintheilung, oder auf die Staatsverwaltung im Allgemeinen und die Normen derselben sich beziehen, wie auch in Gegenständen der Gesetzgebung und allgemeiner Verordnungen, müssen (sofern nicht bei Gegenständen des Departements der auswärtigen Angelegenheiten oder des Kriegswesens die Natur der Sache eine Ausnahme begründet) in dem geheimen Rathe zur Berathung vorgetragen und, mit dessen Gutachten begleitet, an den König gebracht werden.

\section{Fünftes Kapitel. \\ Von den Gemeinden.}

Der Gemeindeverband ist die natürliche Grundlage des Staatsverbandes. Er erstreckt sich auf alles, was die Gemeindemarkung umschließt, und äußert seine Wirkung auf alle bürgerliche Verhältnisse, so weit nicht allgemeine Staatsgesetze oder unstreitige besondere Rechte im Wege stehen. Die Gemeinde nimmt das im Verbande stehende Privatvermögen, das sie in der Entrichtung der Staatssteuer vertritt, subsidiarisch in Anspruch. Die Ausübung ihrer Rechte und Pflichten überträgt sie einem, durch Stimmenmehrheit aller Gemeindebürger, aus ihrer Mitte gewählten, bleibenden Gemeinderathe. Dieser hat die ganze Gemeindeverwaltung in Hinsicht auf Ökonomie und Wohlfahrtspolizei, so wie auf äußere Verhältnisse, theils selbst zu besorgen, theils unter seiner Verantwortlichkeit durch andere von ihm bestellte Personen besorgen zu lassen. In jeder Stadt- oder Dorfgemeinde steht ein Mitglied des Rathes als Vorsitzer desselben und als erster Vorsteher an der Spitze der Verwaltung; er hat zugleich die Staatsangelegenheiten, so weit sie die Gemeinde insbesondere berühren, zu besorgen, und ist in dieser Hinsicht Regierungsbeamter. Ein Ausschuß der Bürgerschaft, dessen Mitglieder nach periodischen Wahlen nothwendig wechseln, ist zu anhaltender Aufmerksamkeit auf das gemeine Beste verpflichtet. In wichtigern Fällen wird durch seinen Widerspruch ein Beschluß des Gemeinderaths in seiner Wirkung gehemmt, durch seine Zustimmung aber theils dessen Amtsgewalt ergänzt, theils auch eine Cognition höherer Stellen entbehrlich gemacht. Das Aufsichts- und Leitungsrecht der Regierung äußert sich darin, daß sie den ersten Vorsteher auf einen Wahlvorschlag der Gemeinde ernennt, der legalen Besetzung der übrigen Verwaltungsstellen sich versichert und sie durch Bestätigung beglaubigt, die Ökonomieverwaltung durch ihre Prüfung in gesetzlicher Ordnung erhält, und über Beschwerden, besonders über Streitigkeiten zwischen der Verwaltung und dem Ausschusse entscheidet. Die staatsbürgerlichen Angelegenheiten, welchen der Gemeindeverband nicht genügt, werden durch den Amts- und Kreisverband gefördert. Sämmtliche zu einem amtshauptmannschaftlichen Kreise gehörigen Dorfgemeinden bilden die Amtskörperschaft. Ein jeder Kreis hat daher eine adelige, eine städtische Körperschaft und so viel Amtskörperschaften der Dorfgemeinden, als amtshauptmannschaftliche Kreise. Bei der städtischen Corporation nimmt die Kreisstadt die oberste Stelle ein, an der Spitze der Amtskörperschaften stehen die Amtshauptleute. Die adelige Körperschaft jedes Kreises wählt einen Vorsteher und dessen Stellvertreter aus ihrem Mittel. 


\section{Sechstes Kapitel. \\ Von dem Verhältnisse der Kirchen zum Staate.}

Jeder der drei im Königreich bestehenden christlichen Confessionen wird freie öffentliche Religionsausübung, und der volle Genuß ihrer Kirchen-, Schul- und Armenfonds zugesichert.

Die Anordnungen in Betreff der innern kirchlichen Angelegenheiten bleiben der verfassungsmäßigen Autonomie einer jeden Kirche überlassen. Dem Könige gebührt das obersthoheitliche Schutz- und Aufsichtsrecht über die Kirchen. Vermöge desselben können die Verordnungen der Kirchengewalt, ohne vorgängige Einsicht und Genehmigung des Regenten, weder verkündet noch vollzogen werden.

Die Kirchendiener sind in Hinsicht ihrer bürgerlichen Handlungen und Verhältnisse der weltlichen Obrigkeit unterworfen.

\section{Siebentes Kapitel. \\ Von Ausübung der Staatsgewalt.}

Der König vertritt den Staat in allen seinen Verhältnissen gegen auswärtige Staaten. Es kann jedoch, ohne Einwilligung der Stände, durch Verträge mit Auswärtigen kein Theil des Staatsgebiets und Staatseigenthums veräußert, keine neue Last auf das Königreich und dessen Angehörige übernommen, und kein Landesgesetz abgeändert oder aufgehoben, keine Verpflichtung, welche den Rechten der Staatsbürger Eintrag thun würde, eingegangen, namentlich auch kein Handelsvertrag, welcher eine neue gesetzliche Einrichtung zur Folge hätte, und kein Subsidienvertrag zur Verwendung der königlichen Truppen in einem Deutschland nicht betreffenden Kriege geschlossen werden.

Der König wird von den Verträgen und Bündnissen, welche von ihm mit auswärtigen Mächten angeknüpft werden, die Stände in Kenntniß setzen, sobald es die Umstände erlauben.

Ohne Beistimmung der Stände kann kein Gesetz gegeben, aufgehoben, abgeändert oder authentisch erläutert werden.

Die Gerechtigkeitspflege wird im Namen des Königs und unter dessen Oberaufsicht durch collegialisch gebildete Gerichte in gesetzlicher Instanzenordnung verwaltet. Die Gerichte, sowohl die bürgerlichen als die peinlichen, sind innerhalb der Grenzen ihres Berufs unabhängig. Dem Könige steht das Begnadigungsrecht zu.

Die Strafe der Vermögensconfiscation ist allgemein aufgehoben.

Was die Militärverfassung betrifft, so wird die Zahl der zur Ergänzung des Militärs jährlich erforderlichen Mannschaft mit den Ständen verabschiedet. -

\section{Achtes Kapitel. \\ Von dem Finanzwesen.}

Für den Aufwand, welchen die Bedürfnisse des Königs, der Mitglieder des königlichen Hauses und der Hofstaat erfordern, wird, so weit solcher durch den Ertrag der Chatoullengüter nicht gedeckt wird, auf die Regierungszeit eines jeden Königs eine theils in Geld, theils in Naturalien bestehende Civilliste verabschiedet.

Güter, die zum Privateigentum der königlichen Familie gehören, liefern zu den allgemeinen Landeslasten ihren Beitrag. 
So weit der Ertrag der fiscalischen Einkünfte, der Kammergüter und Amtsökonomien, der landesherrlichen Forsten und Flößen, der Berg- und Hüttenwerke, der Münze, die Einkünfte vom Post- und Zeitungswesen, von Lehnverreichungen und Sporteln nicht zureicht, wird der Staatsbedarf durch Steuern bestritten. Ohne Bewilligung der Stände kann weder in Kriegs-, noch in Friedenszeiten eine directe oder indirecte Steuer ausgeschrieben oder erhoben werden. Dem Ansinnen einer Steuerbewilligung muß jedesmal eine genaue Nachweisung über die Nothwendigkeit oder Nützlichkeit der zu machenden Ausgaben, über die Verwendung der frühern Staatseinnahmen und deren Unzulänglichkeit vorangehen. Deshalb ist ein Hauptetat den Ständen zur Prüfung vorzulegen. Der von den Ständen angenommene Hauptetat ist in der Regel auf drei Jahre giltig.

Die Staatsschuld wird unter die Gewährleistung der Stände gestellt.

\section{Neuntes Kapitel.}

Von den Landständen.

Die Stände sind berufen, die Rechte des Landes in dem durch die die Verfassung bestimmten Verhältnisse zum Regenten geltend zu machen. Vermöge dieses Berufs haben sie bei Ausübung der Gesetzgebungsgewalt durch ihre Einwilligung mitzuwirken; in Beziehung auf Mängel oder Mißbräuche bei der Staatsverwaltung, ihre Wünsche, Vorstellungen und Beschwerden dem Könige vorzutragen; wegen verfassungswidrigen Handlungen Klage anzustellen; die, nach gewissenhafter Prüfung für nothwendig erkannten Steuern zu bewilligen, und überhaupt das unzertrennliche Wohl des Königs und des Vaterlandes mit treuer Anhänglichkeit an die Grundsätze der Verfassung zu befördern.

Der König wird aller drei Jahre die Versammlung der Stände einberufen, und außerordentlich, so oft es zur Erledigung wichtiger oder dringender Landesangelegenheiten erforderlich ist.

Die Stände theilen sich in zwei Kammern. Die erste Kammer besteht:

1) aus den mündigen Prinzen des königlichen Hauses;

2) aus einem Mitgliede des Domcapitels zu Meißen;

3) aus einem Mitgliede der Universität Leipzig, welche zwei der König auf Lebenszeit ernennt;

4) aus den Häuptern der fürstlichen und gräflichen Linien von Schönburg;

5) aus dem Grafen Solms-Wildenfels;

6) aus den Standesherren zu Königsbrück und Reibersdorf;

7) aus dem Decan des Domstifts St. Petri zu Budissin;

8) aus den beiden Landesältesten;

9) aus dem Landesbestallten;

10) aus den Klostervoigten zu Marienstern und Marienthal, und

11) aus den vom Könige erblich oder auf Lebenszeit ernannten Mitgliedern. Zu erblichen Mitgliedern wird der König nur solche Grundbesitzer aus dem ritterschaftlichen Adel ernennen, welche von einem, mit Fideikommisse belegten, nach dem Rechte der Erstgeburt sich vererbenden Grundvermögen im Königreiche, jährlich eine reine Rente von 6000 Rthlrn. beziehen. Die lebenslänglichen Mitglieder werden vom Könige, ohne Rücksicht auf Geburt und Vermögen, aus den würdigsten Staatsbürgern ernannt. Die Zahl sämmtlicher von dem Könige erblich oder lebenslänglich ernannter Mitglieder darf die Zahl der übrigen Mitglieder der ersten Kammer nicht übersteigen; 
Die zweite Kammer ist zusammengesetzt:

1) aus den gewählten Mitgliedern der adeligen Körperschaft eines jeden Kreises;

2) aus den gewählten Abgeordneten von jeder der Städte Leipzig, Dresden, Chemnitz, Zwickau, Freiberg, Meißen, Plauen, Bautzen, Löbau, Camenz und Zittau;

3) aus den Abgeordneten der städtischen Kreiskörperschaften in den vier Kreisen der alten Erblande;

4) aus den gewählten Abgeordneten der Amtskörperschaften;

Der Eintritt in die erste Kammer geschieht nach erreichter Volljährigkeit.

In die zweite Kammer kann keiner gewählt werden, der nicht 30 Jahr alt ist.

Staatsdiener können nicht innerhalb des Bezirks ihrer Amtshauptmannschaft, und

Kirchendiener nicht innerhalb des Bezirks, in welchem sie wohnen, gewählt werden.

Die Wahlmänner eines Kreises, eines amtshauptmannschaftlichen Bezirks oder einer

Stadt, sind in Ansehung der Person des Abgeordneten nicht auf ihren Wahlbezirk beschränkt; sie können anderswo wohnenden Staatsbürgern ihre Stimme geben. Der Gewählte ist als Abgeordneter nicht des einzelnen Wahlbezirks, sondern des ganzen Landes anzusehen.

Alle sechs Jahre muß eine neue Wahl der Abgeordneten vorgenommen werden; die bisherigen sind wieder wählbar.

Die erste Kammer wird durch Anwesenheit der Hälfte, die zweite Kammer durch das Erscheinen von zwei Drittheilen ihrer Glieder als vollständig besetzt angesehen. Sollte bei Einrufung des Landtags eine der beiden Kammern nicht in dieser Anzahl zusammen kommen, so wird sie als einwilligend in die Beschlüsse der andern angesehen. Doch steht es in diesem Falle den erschienen Mitgliedern der unvollzähligen Kammer frei, den Sitzungen der andern mit Stimmrecht beizuwohnen.

Jede Kammer hat einen Präsidenten und einen Vicepräsidenten, deren Amt bis zum Ablaufe des sechsjährigen Zeitraums dauert. Den Präsidenten der ersten Kammer ernennt der König ohne Vorschlag; für die Stelle des Vicepräsidenten werden von der ersten Kammer drei ihrer Mitglieder durch absolute Stimmenmehrheit gewählt, aus welchen der König eins ernennt. Eben so wählt die zweite Kammer aus ihrer Mitte drei Mitglieder zur Stelle ihres Präsidenten, und wenn hierauf die königliche Ernennung erfolgt ist, auf gleiche Weise zu dem Amte des Vicepräsidenten, welchen der König ebenfalls aus den hierzu vorgeschlagenen drei Mitgliedern ernennt. Jede der Kammern wählt auf die Dauer eines Landtags einen oder mehrere Secretaire aus ihrer Mitte.

Die Sitzungen der zweiten Kammer sind öffentlich; auch hat sie ihre Verhandlungen durch den Druck bekannt zu machen. Von der ersten Kammer muß das letztere ebenfalls geschehen.

Die Sitzungen werden geheim; theils auf das Begehren der Minister und königl. Commissare bei Vorträgen, die sie, ihrer Erklärung nach, im Namen des Königs zu machen haben, und welche nur im Falle einer solchen Erklärung für amtliche Außerungen zu halten sind; theils auf den Antrag von wenigstens drei Mitgliedern, wenn diesen die Mehrheit der Kammer beitritt.

Die Minister, Geheimenräthe mit Sitz und Stimme, so wie die Directoren der Landescollegien und deren Departements sind befugt, den Verhandlungen der beiden Kammern beizuwohnen und an den Berathschlagungen Theil zu nehmen.

Nur den Ministern oder königlichen Commissairen, den Berichtserstattern der ständischen Commissionen und den Mitgliedern, welche einen Gegenstand zur Berathung in Antrag zu bringen haben, steht die Befugniß zu, schriftliche Reden in der Versammlung abzulesen. Außerdem finden blos mündliche Verhandlungen statt.

Gesetzentwürfe können von dem Könige an die Stände und umgekehrt von den Ständen an den König gebracht werden. Der König allein sanctionirt und verkündigt 
die Gesetze, unter Anführung der Vernehmung des geheimen Raths und der erfolgten Zustimmung der Stände.

Alle dergleichen Anträge sind, ehe sie zur Berathung in der Versammlung kommen können, an Commissionen zu verweisen, welche über deren Inhalt Vortrag zu erstatten ist.

Die Beschlüsse werden nach der Stimmenmehrheit, welche nach Beschaffenheit des Gegenstandes eine absolute oder relative seyn kann, abgefaßt, so daß im Falle der Stimmengleichheit der Präsident den Ausschlag giebt. Bei der Abänderung eines Punktes der Verfassung ist aber die Beistimmung von zwei Drittheilen der anwesenden Mitglieder in beiden Kammern nothwendig.

Die zum Wirkungskreise der Stände gehörigen Angelegenheiten werden in jeder Kammer besonders verhandelt. Doch können, um eine Ausgleichung verschiedner Ansichten $\mathrm{zu}$ versuchen, beide Kammern sich mit einander zu vertraulichen Besprechungen ohne Protocollführung und Beschlußnahme, vereinigen.

Es hängt von dem Könige ab, Gesetzesentwürfe oder andere Vorschläge an die erste oder an die zweite Kammer zu bringen; nur die Verwilligung von Abgaben gelangt zuerst an die zweite Kammer.

Die von der einen Kammer gefaßten Beschlüsse werden der andern zur gleichmäßigen Berathung mitgetheilt. Nur zur Ausübung des Rechts der Petitionen und Beschwerden, so wie zu einer Anklage wegen verletzter Verfassung, ist jede Kammer auch einzeln berechtigt.

Die Kammer, an welche die Mittheilung geschieht, kann den Antrag der mittheilenden verwerfen oder annehmen, und zwar entweder unbedingt, oder mit beigefügten Modificationen. Die Verwerfung muß aber jederzeit mit Anführung der Gründe geschehen. Von dieser Regel macht die Abgabenverwilligung eine Ausnahme in folgenden Punkten:

1) Eine Abgabenverwilligung wird in der zweiten Kammer in Berathung gezogen und, nach vorgängiger vertraulicher Besprechung mit der ersten Kammer, Beschluß darüber in der zweiten gefaßt.

2) Dieser Beschluß wird sodann der ersten Kammer mitgetheilt, welche denselben nur im Ganzen, ohne Veränderung annehmen oder verwerfen kann;

3) Erfolgt das letztere; so werden die bejahenden und die verneinenden Stimmen beider Kammern zusammen gezählt, und nach der Mehrheit sämmtlicher Stimmen wird alsdenn der Ständeschluß gefaßt. Würde in diesem Falle Stimmengleichheit eintreten; so hat der Präsident der zweiten Kammer die Entscheidung.

In allen andern Fällen gilt der Grundsatz, daß nur solche Beschlüsse, worüber beide Kammern, nach gegenseitiger Mittheilung, einverstanden sind, an den König gebracht und von dem Könige bestätigt werden können.

Der von der einen Kammer verworfene Antrag der andern kann auf demselben Landtage nicht wiederholt werden.

Kein Mitglied der beiden Kammern kann, während der Dauer der Ständeversammlung, ohne Einwilligung der betreffenden Kammer zu Verhaft gebracht werden, den Fall der Ergreifung auf frischer That wegen eines Verbrechens ausgenommen.

Niemand kann wegen seiner in der Ständeversammlung gehaltenen Vorträge und gegebenen Abstimmungen zur Verantwortung gezogen werden. Jedoch sind Beleidigungen oder Verläumdungen der Regierung, der Ständeversammlung oder einzelner Personen, der Bestrafung nach den bestehenden Gesetzen, in dem ordentlichen Wege des Rechts unterworfen.

Verfehlungen gegen die Gesetze des Anstandes oder der innern Polizei, oder gegen die Geschäftsvorschriften, hat der Präsident zu bemerken, und, wenn sie bedeutend sind, solche zur Kenntniß der Kammer zu bringen, welche, nach Beschaffenheit der Um- 
stände, ihre Mißbilligung ausdrücken, Verweis ertheilen, oder auch Widerruf verlangen können.

Dem Könige steht das Recht zu, die Versammlung zu vertagen oder ganz aufzulösen. Im Falle der Auflösung wird spätestens binnen 6 Monaten eine neue Versammlung einberufen. Es ist hierzu eine neue Wahl der Abgeordneten nöthig, bei welcher jedoch die vorigen Mitglieder wieder gewählt werden können.

So lange die Stände nicht versammelt sind, besteht, als Stellvertreter derselben, ein Ausschuß für diejenigen Geschäfte, deren Besorgung von einem Landtage zum andern zur ununterbrochenen Wirksamkeit der Repräsentanten des Landes nothwendig ist. Der ständische Ausschuß besteht aus 12 Personen, nehmlich den Präsidenten der beiden Kammern, zwei Mitgliedern aus der ersten und acht aus der zweiten Kammer. Die Wahl derselben geschieht von den zu diesem Zwecke vereinigten Kammern nach relativer Stimmenmehrheit. Sechs Mitglieder des Ausschusses, die Präsidenten der beiden Kammern eingeschlossen, müssen in Dresden anwesend seyn. Bei jeder Ständeversammlung hat der Ausschuß über dasjenige, was von ihm in der Zwischenzeit verhandelt worden ist, in einem Zusammentritte beider Kammern Rechenschaft abzulegen. Die Verrichtungen des Ausschusses hören mit der Eröffnung eines neuen Landtags auf.

\section{Zehntes Kapitel. \\ Von dem Staatsgerichtshofe.}

Zum gerichtlichen Schutze der Verfassung wird ein Staatsgerichtshof errichtet. Diese Behörde erkennt über Unternehmungen, welche auf den Umsturz der Verfassung gerichtet sind und über Verletzung einzelner Punkte der Verfassung. Sie besteht aus einem Präsidenten und 12 Richtern, wovon der König den Präsidenten und 6 Richter aus den Mitgliedern der höhern Gerichte, die Ständeversammlung aber die andere Hälfte, nebst drei Stellvertretern im Zusammentritte beider Kammern außerhalb ihrer Mitte wählt. Eine Anklage vor dem Staatsgerichtshofe kann geschehen gegen einzelne Mitglieder der Stände und des Ausschusses, und von den Ständen sowohl gegen Minister, Collegienchefs, höhere Beamte, als auch gegen Mitglieder der Ständeversammlung. Anklage und Vertheidigung geschieht öffentlich. Die Protokolle werden mit den Abstimmungen und Beschlüssen durch den Druck bekannt gemacht. 